\title{
Selective Participation of Somatodendritic HCN Channels in Inhibitory But Not Excitatory Synaptic Integration in Neurons of the Subthalamic Nucleus
}

\author{
Jeremy F. Atherton, ${ }^{1 \star}$ Katsunori Kitano, ${ }^{2,3 *}$ Jerome Baufreton, ${ }^{4}$ Kai Fan, ${ }^{2}$ David Wokosin, ${ }^{1}$ Tatiana Tkatch, ${ }^{1,5}$ \\ Ryuichi Shigemoto, ${ }^{6,7}$ D. James Surmeier, ${ }^{1}$ and Mark D. Bevan ${ }^{1,2}$ \\ ${ }^{1}$ Department of Physiology, Northwestern University, Chicago, Illinois 60611, ${ }^{2}$ Department of Biomedical Science, Sheffield University, Sheffield S10 2TN, \\ United Kingdom, ${ }^{3}$ Department of Human and Computer Intelligence, Ritsumeikan University, Shiga 525-8577, Japan, ${ }^{4}$ Unité Mixte de Recherche Centre \\ National de la Recherche Scientifique 5227, 33076 Bordeaux Cedex, France, ${ }^{5}$ Department of Neuroscience and Brain Technologies, Italian Institute of \\ Technology, 16163 Genova, Italy, and ${ }^{6}$ National Institute for Physiological Sciences and 7 School of Life Science, The Graduate University for Advanced \\ Studies, Myodaiji, Okazaki 444-8787, Japan
}

The activity patterns of subthalamic nucleus (STN) neurons are intimately linked to motor function and dysfunction and arise through the complex interaction of intrinsic properties and inhibitory and excitatory synaptic inputs. In many neurons, hyperpolarizationactivated cyclic nucleotide-gated (HCN) channels play key roles in intrinsic excitability and synaptic integration both under normal conditions and in disease states. However, in STN neurons, which strongly express HCN channels, their roles remain relatively obscure. To address this deficit, complementary molecular and cellular electrophysiological, imaging, and computational approaches were applied to the rat STN. Molecular profiling demonstrated that individual STN neurons express mRNA encoding several HCN subunits, with HCN2 and 3 being the most abundant. Light and electron microscopic analysis showed that HCN2 subunits are strongly expressed and distributed throughout the somatodendritic plasma membrane. Voltage-, current-, and dynamic-clamp analysis, two-photon Ca ${ }^{2+}$ imaging, and computational modeling revealed that $\mathrm{HCN}$ channels are activated by $\mathrm{GABA}_{\mathrm{A}}$ receptor-mediated inputs and thus limit synaptic hyperpolarization and deinactivation of low-voltage-activated $\mathrm{Ca}^{2+}$ channels. Although $\mathrm{HCN}$ channels also limited the temporal summation of EPSPs, generated through two-photon uncaging of glutamate, this action was largely shunted by GABAergic inhibition that was necessary for HCN channel activation. Together the data demonstrate that HCN channels in STN neurons selectively counteract $\mathrm{GABA}_{\mathrm{A}}$ receptor-mediated inhibition arising from the globus pallidus and thus promote single-spike activity rather than rebound burst firing.

\section{Introduction}

The firing patterns of subthalamic nucleus (STN) neurons are highly correlated with normal movement and abnormal movement in Parkinson's disease and are generated through the dynamic, nonlinear interplay between intrinsic and synaptic conductances (Crossman, 2000; Brown, 2003; Wichmann and DeLong, 2003; Bevan et al., 2006). In many classes of nerve cell, hyperpolarization-activated cyclic nucleotide-gated (HCN) channels underlie a key conductance that contributes to intrinsic activity and sculpts the integration of synaptic inputs (Robinson and Siegelbaum, 2003; Baruscotti and DiFrancesco, 2004; Biel et

Received July 22, 2010; revised 0ct. 1, 2010; accepted 0ct. 11, 2010.

This work was supported by National Institutes of Health-National Institute of Neurological Disorders and Stroke Grants NS41280 (M.D.B.) and NS040705 (M.D.B., D.J.S.) and La Fondation de France (J.B.). We thank Dr. Sankari Ramanathan for cell harvesting, Lennell Roberts and Christopher Hill for electron microscopic imaging, Drs. Nadia Urbain and Ariane Menard for the in vivo-like inhibitory conductance waveform, and Prof. Andreas Ludwig for provision of HCN2-deficient mice.

*J.F.A. and K.K. contributed equally to this work.

Correspondence should be addressed to Dr. Mark D. Bevan, Department of Physiology, Northwestern University, 303 East Chicago Avenue, Chicago, IL 60611. E-mail: m-bevan@northwestern.edu.

DOI:10.1523/JNEUROSCI.3898-10.2010

Copyright $\odot 2010$ the authors $\quad 0270-6474 / 10 / 3016025-16 \$ 15.00 / 0$ al., 2009). However in STN neurons, which express HCN channels at high levels (Santoro et al., 2000; Notomi and Shigemoto, 2004), their role is poorly understood because they do not contribute to the characteristic autonomous activity of STN neurons, and their role in (certain forms of) synaptic integration appears minimal (Bevan and Wilson, 1999; Beurrier et al., 2000; Do and Bean, 2003; Baufreton et al., 2005).

The molecular and biophysical properties of native $\mathrm{HCN}$ channels have been extensively characterized (Robinson and Siegelbaum, 2003; Baruscotti and DiFrancesco, 2004; Biel et al., 2009). Native HCN channels comprise homotetramers or heterotetramers of up to four subunits (HCN1-4), activate progressively with hyperpolarization, and are modulated directly by cAMP. HCN channels invariably mediate depolarization because the equilibrium potential of their mixed cation current is approximately $-30 \mathrm{mV}$. HCN channels subserve a range of neuronal functions. Thus, $\mathrm{HCN}$ channels contribute oscillatory properties to neurons and neuronal networks (Lüthi and McCormick, 1998; Bennett et al., 2000; Ludwig et al., 2003; Chan et al., 2004; Garden et al., 2008), regulate the location dependence of synaptic potential magnitude and time course (Magee, 1998, 1999; Williams and 
Stuart, 2000; Williams et al., 2003; Angelo et al., 2007), oppose bistability and $\mathrm{Ca}^{2+}$ channel-mediated electrogenesis (Pape and McCormick, 1989; Lüthi and McCormick, 1998; Williams et al., 2002; Tsay et al., 2007), and mediate homeostatic adjustments in intrinsic excitability (Fan et al., 2005). Furthermore, HCN channel dysregulation may contribute to disorders like epilepsy and Parkinson's disease (Shah et al., 2004; Kole et al., 2007; Shin et al., 2008; Meurers et al., 2009).

The functional roles of HCN channels are related to a variety of factors, including their subunit composition, compartmental expression pattern, voltage dependence, kinetics, and interaction with intrinsic and synaptic conductances (Robinson and Siegelbaum, 2003; Baruscotti and DiFrancesco, 2004; Biel et al., 2009). Therefore, to address the specific roles of HCN channels in STN neurons, we applied the following: (1) singlecell molecular profiling to determine the subunit expression pattern, (2) immunocytochemistry to determine the plasma membrane expression pattern, (3) patch-clamp recording to determine the biophysical properties of HCN channels and their contribution to excitability, (4) dynamic-clamp and two-photon laser-scanning uncaging (2PLU) of glutamate to determine their role in the integration of somatic inhibitory and dendritic excitatory inputs, respectively, (5) two-photon laserscanning microscopy (2PLSM) of a $\mathrm{Ca}^{2+}$ indicator dye to determine their regulation of dendritic $\mathrm{Ca}^{2+}$ dynamics, and (6) computational modeling to examine the interaction of $\mathrm{HCN}$ and other ion channels.

\section{Materials and Methods}

This study used tissue prepared from male Sprague Dawley or Wistar rats [postnatal day 16 (p16) to adult] and adult C57BL/6 HCN2 wild-type and deficient mice (Ludwig et al., 2003). Procedures were performed in accordance with the policies of the Society for Neuroscience, the National Institutes of Health, the 1986 UK Animals (Scientific Procedures) Act, and the Institutional Animal Care and Use Committees of Bordeaux, Northwestern, and Sheffield Universities and the Graduate University for Advanced Studies, Okazaki, Japan.

\section{Single-cell molecular profiling}

STN neurons (p16-25) were acutely isolated and subjected to molecular profiling using the single-cell reverse transcription PCR technique (scRTPCR), as described previously (Tkatch et al., 2000; Ramanathan et al., 2008). The results of scRTPCR were expressed as a fraction of cells with detectable mRNA levels. The detection of mRNA was based on the presence of a clearly visible band of the appropriate size in an ethidium bromide-stained gel. To ensure consistent efficacy of reverse transcriptase, all experiments were performed with the same batch of enzyme. HCN1 mRNA (GenBank accession AF247450) was detected with a pair of primers ATGCCTCTCTTTGCTAACGC (position 1458) and TATTCCTCCAAGACCTCGTTGAA (position 1476), which gave a PCR product of $311 \mathrm{bp}$. HCN2 mRNA (GenBank accession AF247451) was detected with a pair of primers TTCCGCCAGAAGATCCACGATTA (position 1318) and GAACACGTGCGACTTACTCATAA (position 832), which gave a PCR product of $185 \mathrm{bp}$. HCN3 mRNA (GenBank accession AF247452) was detected with a pair of primers GTCGGAGAACAGCCAGTGTAA (position 1496) and TGAGCGTCTAGCAGATCGAG (position 1928), which gave a PCR product of $452 \mathrm{bp}$. HCN4 mRNA (GenBank accession AF247453) was detected with a pair of primers ATCAACGGCATGGTGAATAACTC (position 1584) and TGCCCTGGTAGCGGTGTTC (position 1893), which gave a PCR product of $328 \mathrm{bp}$.

\section{Immunohistochemical analysis of HCN2 subunit expression}

The rabbit polyclonal HCN2 antibody used in this study was raised against glutathione $\mathrm{S}$-transferase fusion proteins containing the $\mathrm{C}$ terminus of rat HCN2 (amino acid residues 797-862), as described previously (Notomi and Shigemoto, 2004). For immunization, HCN2 fusion pro- tein was purified by SDS-PAGE. The gel fragments containing the purified fusion protein were emulsified with Freund's complete (first immunization) or incomplete (second immunization) adjuvant (Nacalai Tesque) and injected subcutaneously into rabbits ( $500 \mu \mathrm{g}$ of fusion protein per animal) at intervals of 4 weeks. From antisera collected 2 weeks after the second injection, HCN2 antibody was affinity purified, first using Protein G-Sepharose (GE Healthcare) and then CNBr-activated Sepharose 4B (GE Healthcare) coupled to the HCN2 fusion protein. The specificity of immunostaining with the HCN2 antibody was verified using an HCN2 gene-deficient mouse (Ludwig et al., 2003) (Fig. 1). Adult wild-type and HCN2 gene-deficient (Ludwig et al., 2003) mice were deeply anesthetized with pentobarbital and perfused with PBS $(0.01 \mathrm{M}$ phosphate, $\mathrm{pH}$ 7.4) for $1 \mathrm{~min}$, followed by fixative containing $4 \%$ paraformaldehyde, $0.05 \%$ glutaraldehyde, and $15 \%$ saturated picric acid in $0.1 \mathrm{~m}$ phosphate buffer (PB; $\mathrm{pH} 7.4$ ) for $15 \mathrm{~min}$. Brains were removed and sections cut on a vibratome (Leica VT1000; Leica Microsystems) at a thickness of $50 \mu \mathrm{m}$. Sections were then incubated at $4^{\circ} \mathrm{C}$ with the HCN2 antibody $(1.0 \mu \mathrm{g} / \mathrm{ml})$ in PBS containing $0.1 \%$ Triton X-100, $0.25 \%$ carrageenan, and $0.5 \%$ normal goat serum (NGS). After several washes in PBS, the sections were incubated with biotinylated goat anti-rabbit IgG antibody (1:200, Vector Laboratories) at room temperature for $1 \mathrm{~h}$ and then with avidin-biotin peroxidase complex (1:100 ABC-Elite; Vector Laboratories) at room temperature for $1 \mathrm{~h}$. Finally, sections were incubated in diaminobenzidine tetrahydrochloride (DAB; Dojindo) and hydrogen peroxide to reveal immunoreactivity. Sections were then mounted on glass slides and prepared for light microscopic analysis.

Rats (p20 to adult; Charles River Laboratories) were deeply anesthetized with ketamine and xylazine and perfused via the ascending aorta with PBS, followed by $300 \mathrm{ml}$ of $4 \%$ paraformaldehyde and $0.05 \%$ glutaraldehyde in PB, followed by $200 \mathrm{ml}$ of PB. Brains were then removed and sectioned in the sagittal plane on a vibratome (Leica VT1000) at 70 $\mu \mathrm{m}$. Sections were freeze-thawed, washed in PBS, and then incubated in PBS containing 10\% NGS for $2 \mathrm{~h}$ before antibody incubations in PBS containing $2 \%$ NGS. Sections were incubated in the HCN2 antibody described above at $0.5 \mu \mathrm{g} / \mathrm{ml}$ for $48 \mathrm{~h}$ at $4^{\circ} \mathrm{C}$. Sections for immunoperoxidase labeling were incubated in biotinylated goat anti-rabbit $\operatorname{IgG}$ (1:200; Vector Laboratories) for $2-3 \mathrm{~h}$, followed by $2 \mathrm{~h}$ in avidin-biotin-peroxidase complex (ABC; 1:100 in PBS; Vector Laboratories), at room temperature. Bound peroxidase was then revealed by incubating the sections in $\mathrm{DAB}$ in the presence of hydrogen peroxide (Vector Laboratories). Sections for immunogold labeling were incubated in goat anti-rabbit IgG coupled to $1.4 \mathrm{~nm}$ gold particles (1:100; Nanoprobes) for 3-4 h at room temperature. Bound gold particles were silver-enhanced using the HQ Silver kit (Nanoprobes). Sections were then postfixed in $1 \%$ osmium tetroxide in PB for $25 \mathrm{~min}$ (immunoperoxidase) or $10 \mathrm{~min}$ (immunogold) and dehydrated through a graded series of alcohol dilutions and embedded in resin (Durcupan ACM Fluka; Sigma-Aldrich) on glass slides.

Immunoreactive structures in the STN were examined using a light microscope equipped with $40-100 \times$ oil-immersion objectives (Zeiss Axioskop, Zeiss), and images were captured using a high-resolution digital camera (Zeiss Axiocam). The dimensions of immunoreactive neuronal somata and putative glial cell bodies were quantified from the digital images using ImageJ (National Institutes of Health) and compared statistically using the Mann-Whitney $U$ test (Prism 5, GraphPad Software). An $\alpha$ value of 0.05 was used as the criterion for determining statistically significant differences. Following light microscopic analysis, areas of the STN were excised, resectioned at $50-70 \mathrm{~nm}$ on an ultramicrotome (UCT, Leica Microsystems), and collected on Pioloform-coated, single-slot copper grids. Ultrathin sections were then stained with $1 \%$ uranyl acetate for $30 \mathrm{~min}$ followed by lead citrate for 2-3 min before being imaged and analyzed with a Jeol 1200 (Jeol USA) or Tecnai G2 Spirit (FEI) transmission electron microscope. Electron microscopic analysis of structures expressing $\mathrm{HCN} 2$ was performed on rat DAB and immunogold-labeled tissue. Tissue close to the surface of the block was analyzed to minimize false-negative labeling due to limited penetration of immunoreagents. The densities of immunogold particles overlying somatic and dendritic compartments were quantified using Reconstruct (http://synapses.clm. utexas.edu/tools/reconstruct/reconstruct.stm). Given that the dendrites 
of STN neurons tend to decrease in diameter with distance from the soma (Kita et al., 1983; Afsharpour, 1985), proximal dendrites were defined arbitrarily as having a diameter $>1 \mu \mathrm{m}$ and distal dendrites as having a diameter $<1 \mu \mathrm{m}$ (two perpendicular diameters were measured for each dendrite, and the minimum diameter was used for analysis). The distance of immunogold particles from the middle of the plasma membrane to the middle of the particle was measured. The best Gaussian fit to the data showed a peak position at $23.3 \mathrm{~nm}$ from the membrane with an SD of $9.9 \mathrm{~nm}$. A gold particle was thus considered to be associated with the plasma membrane if it was located within an area that was up to $43 \mathrm{~nm}$ (peak $+2 \mathrm{SD}$ ) of the cytoplasmic side of the plasma membrane. Immunoparticle densities were measured by calculating the number of gold particles per unit area. Nonspecific labeling was considered to be the density of nuclear labeling. The compartmental distribution of HCN2 labeling was compared statistically using the Kruskal-Wallis test with Dunnett's post hoc analysis (Prism 5) An $\alpha$ value of 0.05 was used as the criterion for determining statistically significant differences.

\section{Electrophysiology}

Slice preparation. Brain slices were prepared from rats, as described previously (Baufreton et al., 2009). Slices were then transferred to a holding chamber containing ACSF, which comprised $126 \mathrm{~mm} \mathrm{NaCl}, 2.5 \mathrm{~mm} \mathrm{KCl}$, $1.25 \mathrm{~mm} \mathrm{NaH}_{2} \mathrm{PO}_{4} \cdot \mathrm{H}_{2} \mathrm{O}, 2 \mathrm{~mm} \mathrm{CaCl}_{2} \cdot 2 \mathrm{H}_{2} \mathrm{O}, 2 \mathrm{~mm} \mathrm{MgSO}_{4} \cdot 7 \mathrm{H}_{2} \mathrm{O}, 10 \mathrm{~mm}$ glucose, and $26 \mathrm{~mm} \mathrm{NaHCO} 3$ (equilibrated with $95 \% \mathrm{O}_{2}$ and $5 \% \mathrm{CO}_{2}$ ) and was maintained at room temperature.

Recording. Brain slices were transferred to a recording chamber that was perfused at a rate of $3-5 \mathrm{ml} \cdot \mathrm{min}^{-1}$ with ACSF that was modified to more closely match rodent brain interstitial fluid. ACSF contained 126 mм NaCl, $3 \mathrm{~mm} \mathrm{KCl}, 1.25 \mathrm{~mm} \mathrm{NaH}_{2} \mathrm{PO}_{4} \cdot \mathrm{H}_{2} \mathrm{O}, 1.6 \mathrm{~mm} \mathrm{CaCl}_{2} \cdot 2 \mathrm{H}_{2} \mathrm{O}, 1.5$ $\mathrm{mM} \mathrm{MgSO} \cdot \cdot 7 \mathrm{H}_{2} \mathrm{O}, 10 \mathrm{~mm}$ glucose, and $26 \mathrm{~mm} \mathrm{NaHCO}_{3}$ (equilibrated with $95 \% \mathrm{O}_{2}$ and $5 \% \mathrm{CO}_{2}$ ) and was heated to $\sim 35^{\circ} \mathrm{C}$. Somatic recordings were made using borosilicate glass micropipettes. Recording pipettes contained $135 \mathrm{~mm} \mathrm{~K}-\mathrm{MeSO}_{4}, 3.8 \mathrm{~mm} \mathrm{NaCl}, 1 \mathrm{~mm} \mathrm{MgCl}_{2} \cdot 6 \mathrm{H}_{2} \mathrm{O}, 10 \mathrm{~mm}$ HEPES, $0.1 \mathrm{~mm} \mathrm{Na}_{4}$ EGTA, $0.4 \mathrm{~mm} \mathrm{Na}_{3} \mathrm{GTP}$, and $2 \mathrm{mM} \mathrm{Mg}_{1.5} \mathrm{ATP}$. For recordings that were combined with $\mathrm{Ca}^{2+}$ imaging, $0.2 \mathrm{~mm}$ Fluo-4 (Invitrogen) was substituted for $\mathrm{Na}_{4}$ EGTA. Alexa 568 hydrazide $(50 \mu \mathrm{M})$ (Invitrogen) was added to pipette solutions to allow visualization of cell bodies, dendrites, and spines under 2PLSM. For perforated-patch recording, gramicidin $\left(15 \mu \mathrm{g} \cdot \mathrm{ml}^{-1}\right)$ was added to the pipette solution $<30 \mathrm{~min}$ before seal formation. The resistance of filled pipettes (as measured in the bath) was 3-4 M $\Omega$ for voltage-clamp experiments, and 5-12 $\mathrm{M} \Omega$ for current-clamp experiments.

Recordings were acquired using Clampex 10 software (Molecular Devices) running on a PC connected to a Multiclamp 700B amplifier (Molecular Devices) via a Digidata 1322A digitizer (Molecular Devices). Recordings were low-pass filtered online at $10 \mathrm{kHz}$ and sampled at 50 $\mathrm{kHz}$. For current-clamp recordings, electrode capacitance was compensated online and voltage errors due to series resistance were either compensated online or corrected offline. For voltage-clamp recordings, electrode capacitance and series resistances of $\sim 10-20 \mathrm{M} \Omega$ were electrically compensated. A liquid junction potential correction of $9 \mathrm{mV}$ was subtracted from whole-cell recordings and $4 \mathrm{mV}$ from perforated-patch recordings. Synthetic $\mathrm{GABA}_{\mathrm{A}} \mathrm{R}$-mediated IPSPs were generated through the patch pipette using a synaptic module (SM-1) conductance injection amplifier (Cambridge Conductance), as previously described (Baufreton et al., 2009).

Imaging. Slices were visualized with standard infrared gradient contrast video microscopy (Infrapatch workstation, Luigs \& Neumann; Eclipse workstation, Nikon) and a $40 \times$ or $60 \times, 0.9$ NA water-immersion objective (Axioskop FS2, Zeiss; E600FN, Nikon) or under 2PLSM (BX51WI, Olympus) and a 60×, 0.9 NA water-immersion lens (Olympus). For 2PLSM, neurons were imaged at $810 \mathrm{~nm}$ with $90 \mathrm{MHz}$ pulse repetition and $\sim 200 \mathrm{fs}$ pulse duration at the sample plane. Two-photon excitation was provided by a Verdi 5W Mira 900F laser (Coherent) that was regulated with a Pockels cell electro-optic modulator (model 350 50-02, Con Optics). Images were acquired using an Ultima 2P dedicated system (Prairie Technologies) running PrairieView and TriggerSync software (Prairie Technologies). Before dye loading, cell bodies were visualized under laser-scanning Dodt contrast imaging (Luigs \& Neumann; Prairie Technologies). Following establishment of the whole-cell configuration, at least 20 min was allowed for the Alexa Fluor dye and Fluo-4 indicator to diffuse into the recorded neuron. High-magnification images of the dendritic arbors of filled neurons were used to guide the selection of locations of $2 \mathrm{PLU}$ and $\mathrm{Ca}^{2+}$ imaging.

2PLU. MNI-caged-L-glutamate ( $5 \mathrm{~mm}$ ) (Tocris Bioscience) in HEPESbuffered ACSF that contained $140 \mathrm{~mm} \mathrm{NaCl}, 23 \mathrm{~mm}$ glucose, $15 \mathrm{~mm}$ HEPES, $3 \mathrm{~mm} \mathrm{KCl}, 1.5 \mathrm{~mm} \mathrm{MgCl}_{2}$, and $1.6 \mathrm{~mm} \mathrm{CaCl}_{2}$, adjusted to $\mathrm{pH} 7.2$ with $1 \mathrm{~m} \mathrm{NaOH}$ (300-310 mOsm), was perfused locally to the recorded cell using a multitube array with a $0.7 \mathrm{~mm}$ mixing tip (MPRE8; Cell MicroControls). The two-photon excitation source for uncaging was a Chameleon-XR tunable laser (Coherent) regulated with a Pockels cell electro-optic modulator and Prairie View and Trigger Sync software (Prairie Technologies). Each chosen location for 2PLU was stimulated at $720 \mathrm{~nm}$ and $20-30 \mathrm{~mW}$ power at the sample plane for $0.5 \mathrm{~ms}$.

2PLSM $\mathrm{Ca}^{2+}$ imaging. Green $(G)$ and red $(R)$ fluorescent line-scan images were acquired at $2.48 \mathrm{~ms}$ per line with $309(0.09 \mu \mathrm{m})$ pixels per line and $4 \mu$ s pixel dwell time. A baseline $\left({ }_{0}\right)$ line scan, with the neuron held at $-70 \mathrm{mV}$ in voltage-clamp mode, was acquired before each protocol. Line-scan data are expressed as $\left(G-G_{0}\right) / R_{0}$.

Drugs. All drugs used were prepared as concentrated stock solutions and stored at $-20^{\circ} \mathrm{C}$. On the day of the experiment, drugs were diluted and applied either through the bath or local perfusion system. GABAergic and glutamatergic synaptic transmission was blocked for all experiments except those involving $2 \mathrm{PLU}$ of MNI-glutamate, for which only GABAergic transmission was blocked. NMDA, AMPA, GABA , and $\mathrm{GABA}_{\mathrm{B}}$ receptors were blocked with $50 \mu \mathrm{M} \mathrm{D}-(-)$-2-amino-5-phosphonopentanoic acid (APV) (Ascent Scientific), $20 \mu \mathrm{M}$ 6,7-dinitroquinoxaline-2,3-dione (DNQX) (Ascent Scientific), $20 \mu \mathrm{M}$ 2-(3-carboxypropyl)3-amino-6-(4 methoxyphenyl)pyridazinium bromide (GABAzine) (Ascent Scientific; SR 95531), and $2 \mu \mathrm{M}$ (2S)-3-[[(1S)-1-(3,4-dichlorophenyl) ethyl]amino-2 hydroxypropyl](phenylmethyl)phosphinic acid (CGP 55845) (Tocris Bioscience), respectively. Voltage-dependent $\mathrm{Na}^{+}\left(\mathrm{Na}_{\mathrm{v}}\right)$ and HCN channels were blocked with $1 \mu \mathrm{M}$ tetrodotoxin citrate (TTX; AscentScientific) and $20 \mu \mathrm{M} 4$-ethylphenylamino-1,2-dimethyl-6-methylaminopyrimidinium chloride (ZD7288; Ascent Scientific; except for a minority of 2PLU experiments in which $50 \mu \mathrm{M}$ ZD7288 was used), respectively. Because ZD7288 may have nonspecific effects (Chevaleyre and Castillo, 2002; Do and Bean, 2003; Felix et al., 2003), 2 mм Cs was also applied in some experiments to block HCN channels (Halliwell and Adams, 1982).

Data analysis. Data were analyzed using Clampfit 10 (Molecular Devices), IgorPro 6 (Wavemetrics), and Prism 5 (GraphPad Software). Line-scan images were analyzed with IgorPro 6. Maximum intensity projections of $Z$-series were generated with ImageJ (National Institutes of Health). Numerical data are presented as mean \pm SD. An $\alpha$ value of 0.05 was used as the criterion for determining statistically significant differences.

\section{Computational modeling}

To further investigate the impact of HCN channels on synaptic integration, we constructed a simplified compartmental model consisting of a single spherical somatic compartment and a four-compartment dendrite, of which each compartment was represented by a cylinder. The suffix $i$ represents the location of each compartment, with 0 for the somatic compartment and 1-4 for each dendritic compartment. The diameter $\left(d_{i}\right)$ and length $\left(l_{i}\right)$ of each compartment are listed in Table 1 . The membrane potential of the $i$ th compartment $V_{i}$ was calculated from the following equation:

$$
\begin{aligned}
c_{\mathrm{m}} A_{i} \frac{d V_{i}}{d t}= & -g_{i-1, i}^{\text {axis }}\left(V_{i}-V_{i-1}\right)-g_{i+1, i}^{\text {axis }}\left(V_{i}-V_{i+1}\right) \\
& -A_{i} I_{i}^{\text {ion }}-I_{i}^{\text {syn }}-I_{i}^{\text {app }},
\end{aligned}
$$

where $c_{\mathrm{m}}$ is unit membrane capacitance $\left(c_{\mathrm{m}}=1 \mu \mathrm{F} \cdot \mathrm{cm}^{-2}\right)$ and $A_{i}$ is the surface area of the $i$ th compartment $\left(\pi d_{i} l_{i}\right) \cdot g^{\text {axis }}$ is the axial conductance between adjacent compartments and was determined from the cytoplasmic resistance $R_{\mathrm{a}}(150 \Omega \cdot \mathrm{cm})$ (Gillies and Willshaw, 
Table 1. Morphological and electrical properties of the STN neuron model

\begin{tabular}{lccccc}
\hline & Soma 0 & Dend 1 & Dend 2 & Dend 3 & Dend 4 \\
\hline Diameter $(\mu \mathrm{m})$ & 10.0 & 2.0 & 1.5 & 1.0 & 0.5 \\
Length & 10.0 & 100.0 & 100.0 & 100.0 & 100.0 \\
$g_{\text {leak }}\left(\mathrm{mS} \cdot \mathrm{cm}^{-2}\right)$ & 0.08 & 0.08 & 0.08 & 0.08 & 0.08 \\
$g_{\text {Nav }}$ & 33.0 & 0.01 & 0.01 & 0.01 & 0.01 \\
$g_{\text {Kv3 }}$ & 69.0 & 0.01 & 0.01 & 0.01 & 0.01 \\
$g_{\text {SK }}$ & 0.1 & 0.1 & 0.1 & 0.1 & 0.1 \\
$g_{\text {Cav3 }}$ & 0.6 & 0.6 & 0.6 & 0.6 & 0.6 \\
$g_{\text {Cav2.2 }}$ & 1.0 & 1.0 & 0.1 & 0.1 & 0.1 \\
$G_{\text {HCN }}($ somatic & 1.2 & 0.0 & 0.0 & 0.0 & 0.0 \\
$G_{\text {HCN }}($ uniform) & 0.2 & 0.2 & 0.2 & 0.2 & 0.2 \\
$G_{\text {HCN }}($ deficient $)$ & 0.0 & 0.0 & 0.0 & 0.0 & 0.0 \\
\hline
\end{tabular}

2006) and the dimensions of adjacent compartments according to the following equation:

$$
g_{i-1, i}^{\text {axis }}=\frac{1}{\frac{2 R_{\mathrm{a}}}{\pi}\left(\frac{l_{i-1}}{d_{i-1}^{2}}+\frac{l_{i}}{d_{i}^{2}}\right)}
$$

$I^{\text {ion }}, I^{\text {syn }}$, and $I^{\text {app }}$ are ionic current density, synaptic current, and applied current, respectively. The ionic current density $I^{\text {ion }}$ was determined by currents flowing through several ion channels, including leak, $\mathrm{Na}_{\mathrm{v}}$, class 3 voltage-dependent $\mathrm{K}^{+}\left(\mathrm{K}_{\mathrm{v}} 3\right)$, small-conductance $\mathrm{Ca}^{2+}$-dependent $\mathrm{K}^{+}$ (SK), class 3 and 2.2 voltage-dependent $\mathrm{Ca}^{2+}\left(\mathrm{Ca}_{\mathrm{v}} 3\right.$ and $\mathrm{Ca}_{\mathrm{v}} 2.2$, respectively), and $\mathrm{HCN}$ channels:

$$
\begin{aligned}
I^{\text {ion }}=-g_{\text {leak }}\left(V-E_{\text {leak }}\right)- & g_{\text {Nav }} m^{3} h\left(V-E_{\mathrm{Na}}\right)-g_{\mathrm{Kv} 3} n^{4}\left(V-E_{\mathrm{K}}\right) \\
& -g_{\mathrm{SK}} r^{2}\left(V-E_{\mathrm{K}}\right)-g_{\mathrm{Cav} 3} p^{2} q\left(V-E_{\mathrm{Ca}}\right) \\
& \quad-g_{\mathrm{Cav} 2.2} v w\left(V-E_{\mathrm{Ca}}\right)-g_{\mathrm{HCN}} f\left(V-E_{\text {cation }}\right) .
\end{aligned}
$$

Gating variables for each ion channel were described by an activation function and a time constant:

$$
\begin{aligned}
\frac{d x}{d t} & =\frac{x_{\infty}(u)-x}{\tau_{x}(u)} \\
x_{\infty}(u) & =\frac{1}{1+\exp \left[\left(u-\theta_{x}\right) / k_{x}\right]} \\
\tau_{x}(u) & =\tau_{x}^{0}+\frac{\tau_{x}^{1}}{\exp \left[\left(u-\phi_{x}^{1}\right) / \sigma_{x}^{1}\right]+\exp \left[\left(u-\phi_{x}^{2}\right) / \sigma_{x}^{2}\right]}
\end{aligned}
$$

where $x$ represents the gating variable and $u$ is membrane potential for a voltage-dependent channel or intracellular $\mathrm{Ca}^{2+}$ concentration for the SK channel. Intracellular calcium concentration obeyed the following equation (Otsuka et al., 2004):

$$
\frac{d\left[\mathrm{Ca}^{2+}\right]_{\mathrm{i}}}{d t}=-\frac{\gamma_{i}}{Z F}\left(I_{\mathrm{Cav} 3}+I_{\mathrm{Cav} 2.2}\right)-K_{\mathrm{Ca}}\left[\mathrm{Ca}^{2+}\right]_{\mathrm{i}},
$$

where $Z$ is the valence of calcium ion (2), $F$ is the Faraday constant, $K_{\mathrm{Ca}}$ is the $\mathrm{Ca}^{2+}$ removal rate $(2 \mathrm{~ms})$, and $\gamma_{i}$ is the ratio of surface area to volume for the ith compartment. Parameters for $\mathrm{Na}_{\mathrm{v}}, \mathrm{K}_{\mathrm{v}} 3, \mathrm{Ca}_{\mathrm{v}} 3$, and SK channels were adopted from the model of Otsuka et al. (2004) with voltagedependent functions shifted by $-7.1 \mathrm{mV}$ for $\mathrm{Na}_{\mathrm{v}}$ and $-5 \mathrm{mV}$ for the others $\left(\theta_{x}, \phi_{x}^{1}\right.$, and $\phi_{x}^{2}$ are changed). Parameters for $\mathrm{Ca}_{\mathrm{v}} 2.2$ channels were adopted from Tsay et al. (2007) except for a shift in voltage dependence of $-5 \mathrm{mV}$. The activation function of HCN channels was based on experimental data. The voltage-dependent time constant of Angelo et al. (2007) was adopted except that the time constant $\tau_{x}^{1}$ was increased from $1600 \mathrm{~ms}$ to $2400 \mathrm{~ms}$. Parameters for each channel are detailed in Table 2. Equilib-

\begin{tabular}{|c|c|c|c|c|c|}
\hline Channel & Parameters & Values & Channel & Parameters & Values \\
\hline $\mathrm{Na}_{\mathrm{v}}$ & $\theta_{m}, k_{m}$ & $-47.1,-8.0$ & $\left(a_{v} 2.2\right.$ & $\theta_{w} k_{w}$ & $-64.0,10.0$ \\
\hline $\mathrm{Na}_{\mathrm{v}}$ & $\tau_{m}^{0}, \tau_{m}^{1}$ & $0.2,3.0$ & $\left(a_{v} 2.2\right.$ & $\tau_{w}^{0}, \tau_{w}^{1}$ & $121.0,0$ \\
\hline $\mathrm{Na}_{\mathrm{v}}$ & $\phi_{m^{\prime}} \sigma_{m}$ & $-58.0,-0.7$ & $\mathrm{Ca}_{\mathrm{v}} 3$ & $\theta_{p}, k_{p}$ & $-61.0,-6.7$ \\
\hline $\mathrm{Na}_{\mathrm{v}}$ & $\theta_{h}, k_{h}$ & $-50.5,6.4$ & $\mathrm{Ca}_{\mathrm{v}} 3$ & $\tau_{p}^{0}, \tau_{p}^{1}$ & $5.0,0.33$ \\
\hline $\mathrm{Na}_{\mathrm{v}}$ & $\tau_{h}^{0}, \tau_{h}^{1}$ & $0,24.5$ & $\mathrm{Ca}_{\mathrm{v}} 3$ & $\phi_{p^{\prime}}^{1} \sigma_{p}^{1}$ & $-32.0,-10.0$ \\
\hline $\mathrm{Na}_{\mathrm{v}}$ & $\phi_{h}^{1}, \sigma_{h}^{1}$ & $-55.0,-15.0$ & $\mathrm{Ca}_{\mathrm{v}} 3$ & $\phi_{p^{\prime}}^{2} \sigma_{p}^{2}$ & $-107.0,15.0$ \\
\hline $\mathrm{Na}_{\mathrm{v}}$ & $\phi_{h}^{2}, \sigma_{h}^{2}$ & $-55.0,16.0$ & $\mathrm{Ca}_{\mathrm{v}} 3$ & $\theta_{q^{\prime}} k_{q}$ & $-95.0,5.8$ \\
\hline $\mathrm{K}_{\mathrm{v}} 3$ & $\theta_{n}, k_{n}$ & $-46.0,-14.0$ & $\mathrm{Ca}_{\mathrm{v}} 3$ & $\tau_{q^{\prime}}^{0} \tau_{q}^{1}$ & $0,400.0$ \\
\hline $\mathrm{K}_{\mathrm{v}} 3$ & $\tau_{n^{\prime}}^{0} \tau_{n}^{1}$ & $0,11.0$ & $\mathrm{Ca}_{\mathrm{v}} 3$ & $\phi_{q^{\prime}}^{1} \sigma_{q}^{1}$ & $-55.0,-15.0$ \\
\hline $\mathrm{K}_{\mathrm{v}} 3$ & $\phi_{n^{\prime}}^{1} \sigma_{n}^{1}$ & $-45.0,-40.0$ & $\mathrm{Ca}_{\mathrm{v}} 3$ & $\phi_{q}^{2}, \sigma_{q}^{2}$ & $-55.0,16.0$ \\
\hline Kv3 & $\phi_{n}^{2}, \sigma_{n}^{2}$ & $-45.0,50.0$ & $\mathrm{HCN}$ & $\theta_{f}, k_{f}$ & $-90.0,8.0$ \\
\hline SK & $\theta_{r}, k_{r}$ & $0.17,-0.08$ & $\mathrm{HCN}$ & $\tau_{f}^{0}, \tau_{f}^{1}$ & $0,2400.0$ \\
\hline SK & $\tau_{r}^{0}, \tau_{r}^{1}$ & $2.0,0.0$ & $\mathrm{HCN}$ & $\phi_{f}^{1}, \sigma_{f}^{1}$ & $-68.0,-22.0$ \\
\hline $\mathrm{Ca}_{\mathrm{v}} 2.2$ & $\theta_{v}, k_{v}$ & $-7.0,-10.0$ & $\mathrm{HCN}$ & $\phi_{f}^{2}, \sigma_{f}^{2}$ & $-68.0,7.0$ \\
\hline $\mathrm{Ca}_{\mathrm{v}} 2.2$ & $\tau_{v}^{0}, \tau_{v}^{1}$ & $3.0,0$ & & & \\
\hline
\end{tabular}
rium potentials $(E)$ were set as follows: $E_{\text {leak }}=-67 \mathrm{mV}, E_{\mathrm{Na}}=50 \mathrm{mV}$, $E_{\mathrm{K}}=-90 \mathrm{mV}$, and $E_{\text {cation }}=-35 \mathrm{mV}$ for the HCN channel. $E_{\mathrm{Ca}}$ was determined by the Nernst equation. To determine the impact of $\mathrm{HCN}$ channel expression and compartmental distribution, three models were investigated: somatic, somatodendritic, and deficient. Respectively, $\mathrm{HCN}$ conductance was restricted to the soma, uniformly expressed in
Table 2. Channel parameters of the STN neuron model

each compartment or entirely absent. The total HCN conductance for each model $\left(\sum_{i} A_{i} g_{\mathrm{HCN}, i}\right)$ was equivalent for the somatic and somatodendritic models. The initial magnitude of conductances in each compartment are detailed in Table 1 and were chosen so that (1) model neurons exhibited typical membrane properties of STN neurons, i.e., autonomous activity of $\sim 10 \mathrm{~Hz}$, voltage sag in response to hyperpolarizing current injection (for models in which HCN channels were expressed) and rebound burst activity; (2) the impact of channel removal was similar to that observed experimentally (Bevan et al., 1999; Beurrier et al., 2000; Hallworth et al., 2003); and (3) action potentials were generated in the soma before propagating into the dendritic compartment, as observed experimentally (Atherton et al., 2008). The maximum conductance of each ion channel in each compartment is indicated in Table 1. $I^{\text {syn }}$ represents excitatory and inhibitory synaptic currents. EPSCs were modeled as a compound of AMPA receptor-mediated and NMDA receptormediated components. The AMPA receptor-mediated EPSC was described by the model of Tsodyks and Markram (1997):

$$
\begin{aligned}
I_{\mathrm{AMPA}}^{\mathrm{yn}} & =g_{\mathrm{AMPA}} e\left(V-E_{\mathrm{AMPA}}\right) \\
\frac{d e}{d t} & =-\frac{e}{\tau}+U r \delta\left(t-t_{\mathrm{AP}}\right), \\
\frac{d r}{d t} & =\frac{1-r-e}{\tau_{\mathrm{rec}}}
\end{aligned}
$$

where $e$ and $r$ represent effective and recovered ratios of neurotransmission, respectively. The decay constant of the EPSC $\tau$ and the recovery time constant $\tau_{\text {rec }}$ were set to $2.5 \mathrm{~ms}$ and $200 \mathrm{~ms}$, respectively. The presynaptic release probability $U$ was $0.2 . t_{\mathrm{AP}}$ represents the timing of the presynaptic action potential.

The NMDA receptor-mediated EPSC was described by the model of Destexhe et al. (1998):

$$
\begin{aligned}
I_{\mathrm{NMDA}}^{\mathrm{ion}} & =g_{\mathrm{NMDA}} s F(V)\left(V-E_{\mathrm{NMDA}}\right) \\
\frac{d s}{d t} & =\alpha T(1-s)-\beta s \\
F(V) & =\frac{1}{1+0.28 \exp (-0.062 V)}
\end{aligned}
$$

where $\alpha^{-1}$ and $\beta^{-1}$ are rise and decay time constants of the open ratio of receptors $(s)$ and were set to $2.0 \mathrm{~ms}$ and $142.8 \mathrm{~ms}$, respectively. The variable $T$ represents presynaptic neurotransmitter release, which was set to $1 \mathrm{~ms}$ after the occurrence of an action potential, and is otherwise 0 . $F(V)$ is a postsynaptic-voltage-dependent function that represents voltage-dependent $\mathrm{Mg}^{2+}$ block. The IPSC mediated by $\mathrm{GABA}_{\mathrm{A}}$ receptors was modeled similarly to AMPA receptors except that a decay time constant of $8.0 \mathrm{~ms}$ was used. Finally, simulation codes were written in C, and numerical integration was performed with the fourth-order RungeKutta method. An integration time step of $0.05 \mathrm{~ms}$ was used, although similar results were obtained with a time step of $0.01 \mathrm{~ms}$. 
A

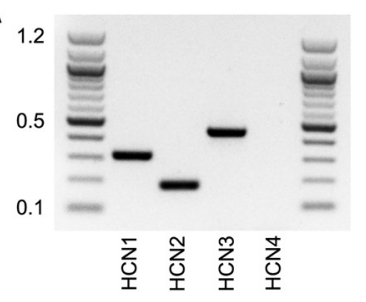

B
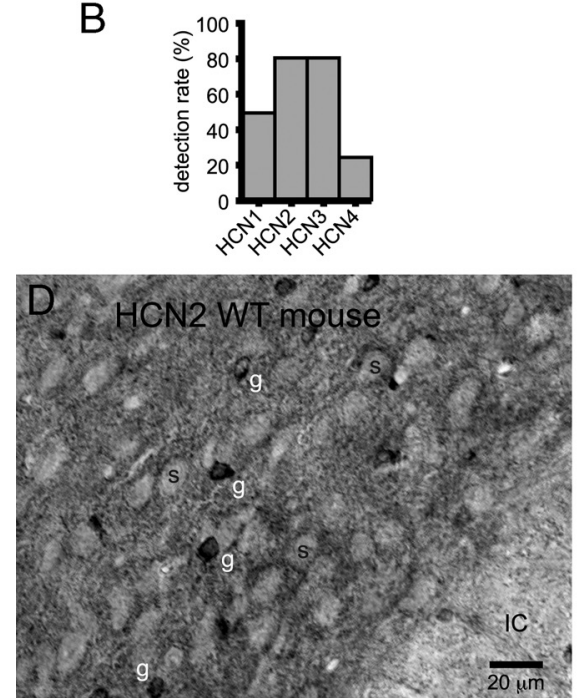
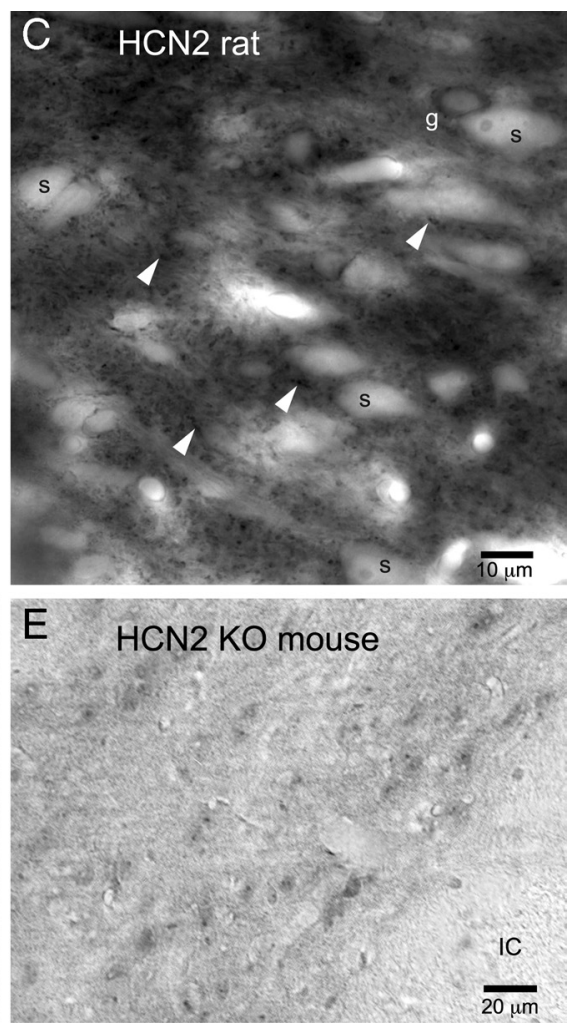

Figure 1. Expression of HCN channels. $\boldsymbol{A}$, Gel from a single STN neuron that expressed HCN1, 2, and 3 mRNA. $\boldsymbol{B}$, sCRTPCR detection rate of HCN1-4 subunits in STN neurons $(n=16)$. C, Light micrograph of rat STN HCN2 immunoreactivity visualized with $\mathrm{DAB}$ and intensified by postfixation with osmium tetroxide. Arrowheads point to small immunoreactive elements in the neuropil. Neuronal somata $(\mathrm{s}$ ) and small glial cells $(\mathrm{g}$ ) were also weakly and strongly labeled, respectively. D, E, STN HCN2 immunoreactivity (as revealed by DAB without postfixation with osmium tetroxide) in a wild-type (WT) and a HCN2 knock-out (HCN2 KO) mouse. The pattern of labeling in the rat and WT mouse STN (labeled as for $C$ ) are similar. However, specific labeling was abolished in the STN of the HCN2 KO mouse.

\section{Results}

\section{STN neurons express multiple HCN subunits}

scRTPCR analysis was performed to determine the pattern of HCN channel subunit mRNA expression in individual acutely isolated STN neurons (Fig. 1A,B). Of 16 cells tested, 8 (50.0\%) expressed detectable levels of HCN1 channel subunit mRNA, 13 (81.3\%) expressed HCN2 and HCN3 subunit mRNA and 4 (25\%) expressed HCN4 subunit mRNA (Fig. 1B).

The STN has previously been shown to most strongly express HCN2 (Monteggia et al., 2000; Santoro et al., 2000; Notomi and Shigemoto, 2004). Light microscopic analysis confirmed that the rat and mouse STN was immunoreactive for HCN2 and demonstrated that STN immunoreactivity was abolished in HCN2-deficient mice (Fig. 1C-E) (Ludwig et al., 2003). Immunoreactivity was present in the somata of STN neurons, smaller-diameter putative glial cells (minimum diameter of STN neurons $=9.6 \pm 1.5 \mu \mathrm{m}, n=54$; minimum diameter of putative glial cells $=6.6 \pm 1.0 \mu \mathrm{m}, n=40$; Mann-Whitney $U$ test, $p<0.05$ ), and fine dendritic- and axonal-like structures (Fig. 1C,D). HCN2 immunoreactivity in other brain regions was also consistent with earlier reports (Monteggia et al., 2000; Santoro et al., 2000; Notomi and Shigemoto, 2004; data not shown).

Given that axons, terminals, and perineuronal oligodendrocytes also express HCN2 subunits (Notomi and Shigemoto, 2004; Boyes et al., 2007), electron microscopic analysis of DAB-labeled tissue was used to determine the expression pattern of HCN2

in the somatodendritic compartment of STN neurons. Small- and large-diameter dendrites and neuronal somata were immunoreactive (Fig. 2 A). Labeled glial cells (putative perineuronal oligodendrocytes) were readily distinguished from the somata of STN neurons on the basis of their well characterized ultrastructural properties, including round/ovoid nuclei with relatively dense clumps of heterochromatin, electron-dense cytoplasm filled with ribosomes, and short strands of Golgi apparatus and endoplasmic reticulum (Ludwin, 1979; data not shown).

To more precisely quantify the relative expression of $\mathrm{HCN} 2$ in each compartment of STN neurons immunogold labeling of HCN2 was analyzed (cf. Lörincz et al., 2002; Holderith et al., 2003; Boyes et al., 2007). Material from $\mathrm{p} 20, \mathrm{p} 41$, and p82 rats were studied to ensure that the expression patterns of HCN2 in juvenile animals (in which physiological measurements were mostly made) were similar to those associated with later stages of development. The pattern of HCN2 expression at the electron microscopic level was similar for material derived from each animal. Thus, the density of HCN2 expression overlying the somatic and large- and small-diameter dendritic plasma membrane of STN neurons was significantly higher than background labeling over neuronal nuclei in each sample (Fig. $2 B-$ $D)$; Kruskal-Wallis and Dunn's multiplecomparison tests, $p<0.05)$. In contrast, the density of HCN2 expression overlying the cytoplasmic component of each compartment was not significantly different from background nuclear labeling (Fig. $2 B-D$ ). To compare the specific membranous expression pattern of HCN2 across the somatodendritic axis, background labeling was subtracted. The pattern of specific HCN2 expression in the somatic and large-/ small-diameter dendritic membrane was not significantly different, and this pattern was consistent for each sample [specific density of HCN2 labeling, in particles per square micrometer: p20: soma $=6.3 \pm 3.9(n=16)$, dendrite $>1.0 \mu \mathrm{m}=6.7 \pm 7.2$ $(n=20)$, dendrite $<1.0 \mu \mathrm{m}=9.2 \pm 9.4(n=28) ; \mathrm{p} 41$ : soma $=$ $10.5 \pm 9.5(n=20)$, dendrite $>1.0 \mu \mathrm{m}=12.0 \pm 9.1(n=21)$, dendrite $<1.0 \mu \mathrm{m}=18.5 \pm 21.7(n=62) ; \mathrm{p} 82$ : soma $=6.9 \pm 4.7$ $(n=15)$; dendrite $>1.0 \mu \mathrm{m}=8.3 \pm 5.7(n=11)$; dendrite $<1.0$ $\mu \mathrm{m}=9.0 \pm 7.9(n=31)$; Kruskal-Wallis and Dunn's multiplecomparison tests, N.S.]. Together these data suggest that HCN2 subunits are expressed throughout the somatodendritic membrane of STN neurons and that this expression pattern is stable over the developmental period of interest.

\section{Activity of $\mathrm{HCN}$ channels during autonomous firing, depolarization, and hyperpolarization}

Previous studies have suggested that HCN channels contribute minimally to autonomous activity of STN neurons or integration of single IPSPs emanating from the globus pallidus (GP) (Bevan and Wilson, 1999; Beurrier et al., 2000; Do and Bean, 2003; Baufreton et al., 2005). To further address this issue, the 
effects of the selective HCN channel blocker ZD7288 on STN neurons recorded in the perforated-patch current-clamp configuration were studied. Application of ZD7288 had no effect on the frequency of autonomous activity (Fig. $3 A$ ) [control $=7.1 \pm 2.4$ $\mathrm{Hz}$; ZD7288 = $6.8 \pm 2.1 \mathrm{~Hz} ; n=9$; Wilcoxon signed-rank (WSR) test, N.S.] or peak of single-spike afterhyperpolarization (control $=-67.2 \pm 6.3 \mathrm{mV}$; ZD7288 = $-67.0 \pm 6.4 \mathrm{mV} ; n=6$; WSR test, N.S.). Furthermore, ZD7288 had no effect on the firing response of STN neurons to small levels of depolarizing current injection (Fig. $3 B$ ) in each of four neurons examined. In contrast, ZD7288 application significantly enhanced the degree of steady-state hyperpolarization in response to current injections equal to or more negative than $-15 \mathrm{pA}$ (Fig. 3C). Because the peak level of hyperpolarization associated with injection of -15 pA was $-74.9 \pm 8.1 \mathrm{mV}$, these data suggest that HCN channels activate when the membrane potential drops just below that associated with autonomous activity.

The effects of $2 \mathrm{~mm} \mathrm{Cs}^{+}$on STN neurons recorded in the perforated-patch configuration were similar to ZD7288. Thus the frequency of autonomous activity $\left(\right.$ control $=10.2 \pm 4.0 \mathrm{~Hz} ; \mathrm{Cs}^{+}=$ $10.8 \pm 5.6 \mathrm{~Hz} ; n=5)$ and single-spike afterhyperpolarization (control $=-68.4 \pm$ $5.1 \mathrm{mV} ; \mathrm{Cs}^{+}=-66.7 \pm 5.6 \mathrm{mV} ; n=5$ ) were little affected. The firing response to moderate depolarizing current injection was little altered (e.g., $+20 \mathrm{pA}$ : control $=$ $19.4 \pm 7.8 \mathrm{~Hz} ; \mathrm{Cs}^{+}=22.6 \pm 10.4 \mathrm{~Hz}$ ), whereas steady-state hyperpolarization in response to hyperpolarizing current injection was greatly increased in each cell tested (e.g., $-15 \mathrm{pA}$ : control $=-69.0 \pm 9.1 \mathrm{mV} ; \mathrm{Cs}^{+}=-79.6 \pm 5.5 \mathrm{mV} ; n=5$ ).

To more accurately quantify the contribution of HCN channel current at voltages associated with and more hyperpolarized than the resting membrane potential, the voltage dependence of activation of HCN channels was characterized under voltage clamp (Fig. 4). TTX was applied to improve voltage control. STN cells were held at $-50 \mathrm{mV}$ for $2 \mathrm{~s}$ before stepping to voltages between $-50 \mathrm{mV}$ and $-120 \mathrm{mV}$. The cells were held at the test potential for $5 \mathrm{~s}$ and then stepped to $-120 \mathrm{mV}$ for $1 \mathrm{~s}$ to evoke a tail current (Fig. 4A). To isolate HCN channel current, the experiments were repeated in the presence of ZD7288. Analysis of ZD7288-sensitive tail currents for the cell shown in Figure 4A revealed an inward current that activated at membrane potentials hyperpolarized to approximately $-60 \mathrm{mV}$. The half-maximal activation voltage $\left(\mathrm{V}^{1 / 2}\right)$ was estimated by sigmoidal fit to be -87.5 $\mathrm{mV}$. Overall, for eight cells tested, the ZD7288-sensitive current displayed minimal activation at $-60 \mathrm{mV}(1.1 \pm 16.8 \%)$ and a $\mathrm{V}_{1 / 2}$ of $-87.1 \pm 4.2 \mathrm{mV}$ (Fig. 4B). Steady-state currents (measured immediately before the step to $-120 \mathrm{mV}$ to measure tail currents) ranged from $-13.4 \pm 10.3 \mathrm{pA}$ at $-70 \mathrm{mV}$ to $-130.1 \pm$ $98.6 \mathrm{pA}$ at $-120 \mathrm{mV}(n=8)$. The activation kinetics of $\mathrm{HCN}$ current were best fit by a double exponential $\left(-90 \mathrm{mV}: A_{1}=\right.$ $35.7 \pm 12.3 \% ; \tau_{1}=430.9 \pm 261.6 \mathrm{~ms} ; A_{2}=64.3 \pm 12.3 \% ; \tau_{2}=$ $2270.0 \pm 866.1 \mathrm{~ms} ; n=6)$. Together these data suggest that (1)

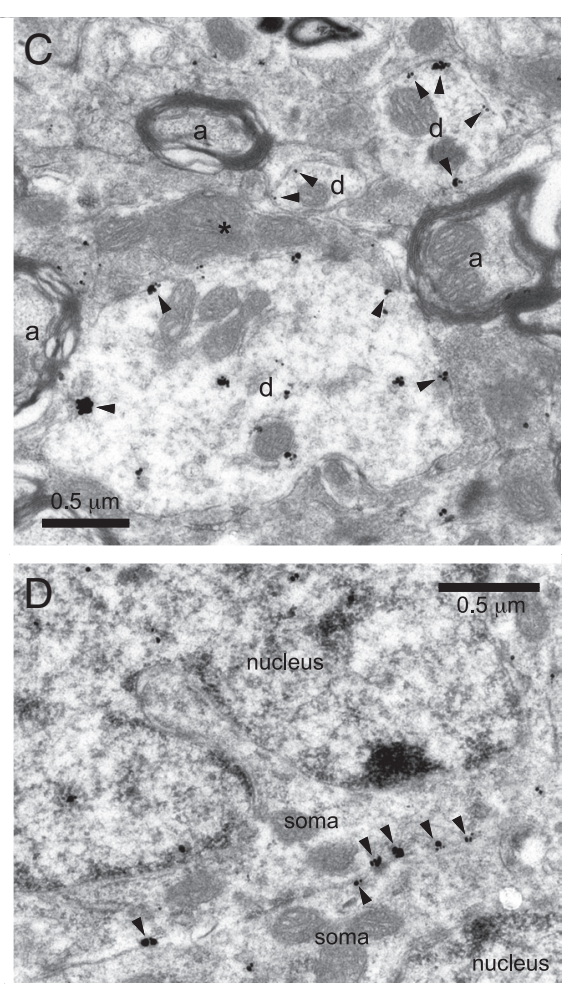

Figure 2. HCN2 immunoreactivity is expressed across the somatodendritic axis of STN neurons. $A$, Electron micrograph of STN dendrites (d) of varying diameters. $\boldsymbol{B}$, The density of HCN2 immunogold particles overlying the somatodendritic membrane (M) pas somatodendritic axis and significantly higher than the densities overlying cytoplasmic $(C)$ or nuclear comneurons. In $C$, a terminal (*) with the morphology of a globus pallidus terminal forms symmetrical synaptic contacts (arrows) with a large-diameter immunoreactive dendrite. In these examples, immunoreactivity was absent from myelinated axons (a). ${ }^{*} p<$ 0.05; box plot: box, $25 \%, 50 \%$, and $75 \%$; whiskers, $10-90 \%$.

HCN channels contribute minimally to excitability and integration of somatic inputs at voltages associated with autonomous oscillation; (2) inputs that hyperpolarize the voltage below the range associated with autonomous activity lead to the activation of HCN channels; and (3) STN HCN channels activate slowly with time constants ranging from several hundred milliseconds to several seconds.

\section{$\mathrm{HCN}$ channels are recruited by and oppose $\mathrm{GABA}_{\mathrm{A}}$ receptor-mediated inhibition}

In many types of neuron, $\mathrm{HCN}$ channels are active at the resting membrane potential and participate in the integration of synaptic inputs (Lüthi and McCormick, 1998; Magee, 1999; Bennett et al., 2000; Williams and Stuart, 2000, 2003; Williams et al., 2002; Ludwig et al., 2003; Chan et al., 2004; Shah et al., 2004; Fan et al., 2005; Angelo et al., 2007; Garden et al., 2008). Although STN HCN channels are apparently not active during autonomous activity, these neurons receive continuous and powerful $\mathrm{GABA}_{\mathrm{A}}$ receptormediated inhibition from the globus pallidus (DeLong, 1990; Crossman, 2000; Hallworth and Bevan, 2005; Tachibana et al., 2008; Karachi et al., 2009). Given that the maximum instantaneous conductance arising from this pathway in rats is estimated to be several hundred nanosiemens and the equilibrium potential of $\mathrm{GABA}_{\mathrm{A}}$ receptor current is more negative than $-80 \mathrm{mV}$ (Bevan et al., 2000, 2002; Baufreton et al., 2009), we hypothesized that $\mathrm{HCN}$ channels may be strongly and dynamically recruited by GABAergic inhibition. Indeed, at $-80 \mathrm{mV}, \mathrm{HCN}$ channels are 


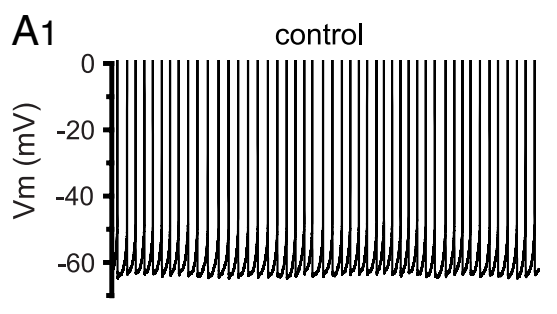

A2
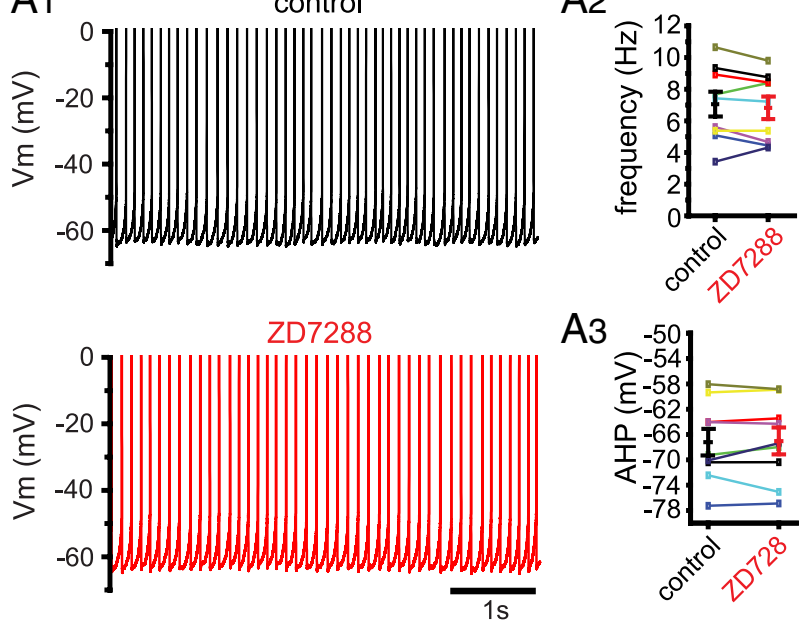

A3
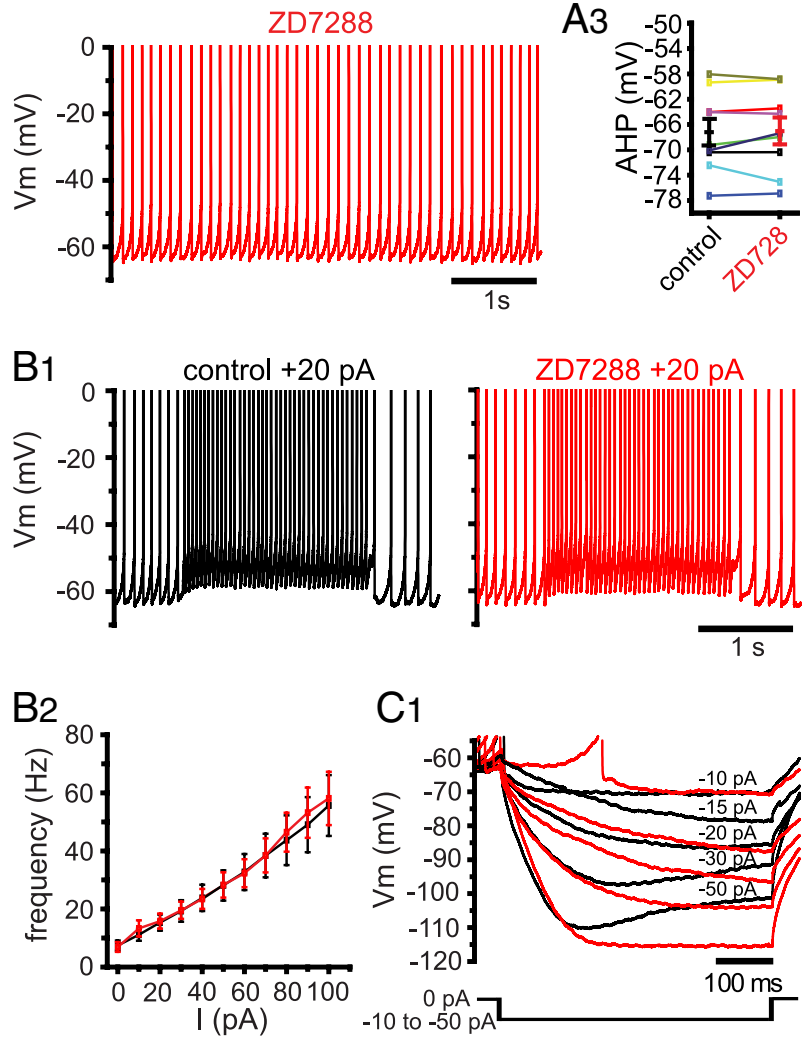

C1

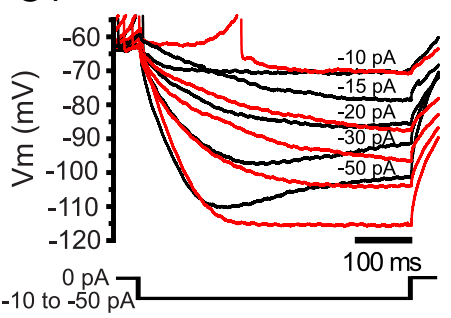

C2

C3
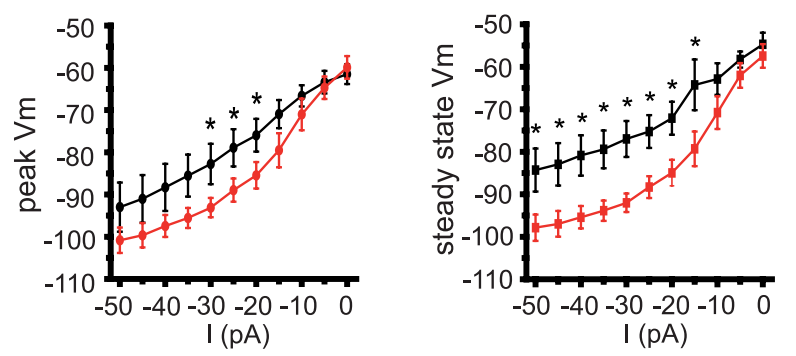

Figure 3. Effects of HCN channel blockade on excitability. $\boldsymbol{A}$, Blockade of HCN channels with ZD7288 had no effect on autonomous activity or magnitude of action potential afterhyperpolarization (AHP) in a representative neuron $(\boldsymbol{A} \mathbf{1})$ or the sample population $(\boldsymbol{A} \mathbf{2}, \mathbf{A} \mathbf{3}$; individual neuron data represented by distinct colors). $\boldsymbol{B}$, Blockade of $\mathrm{HCN}$ channels with ZD7288 did not affect the response of STN neurons to moderate depolarizing current injection either in the representative example neuron (B1) or across the sample population (B2). C, Blockade of HCN channels with ZD7288 (red) increased the degree of hyperpolarization produced by hyperpolarizing current injection in a representative neuron $(\mathbf{C} \mathbf{1})$ and across the sample population $(\boldsymbol{C}, \mathbf{C})$ compared to responses under control conditions (black). Effects on the degree of steady-state hyperpolarization measured at the end of $500 \mathrm{~ms}$ current injection were more consistent than effects on peak hyperpolarization. Action potentials are truncated at $0 \mathrm{mV} ; \mathrm{Vm}$, membrane potential; ${ }^{*} p<0.05$.

$30.2 \pm 12.6 \%$ activated and contribute approximately $-30.6 \pm$ $22.9 \mathrm{pA}$ at steady state $(n=8)$. To test this hypothesis, STN neurons were injected with a $\mathrm{GABA}_{\mathrm{A}}$ receptor-mediated conductance derived from a $10 \mathrm{~s}$ voltage-clamp record of a minimally
A1
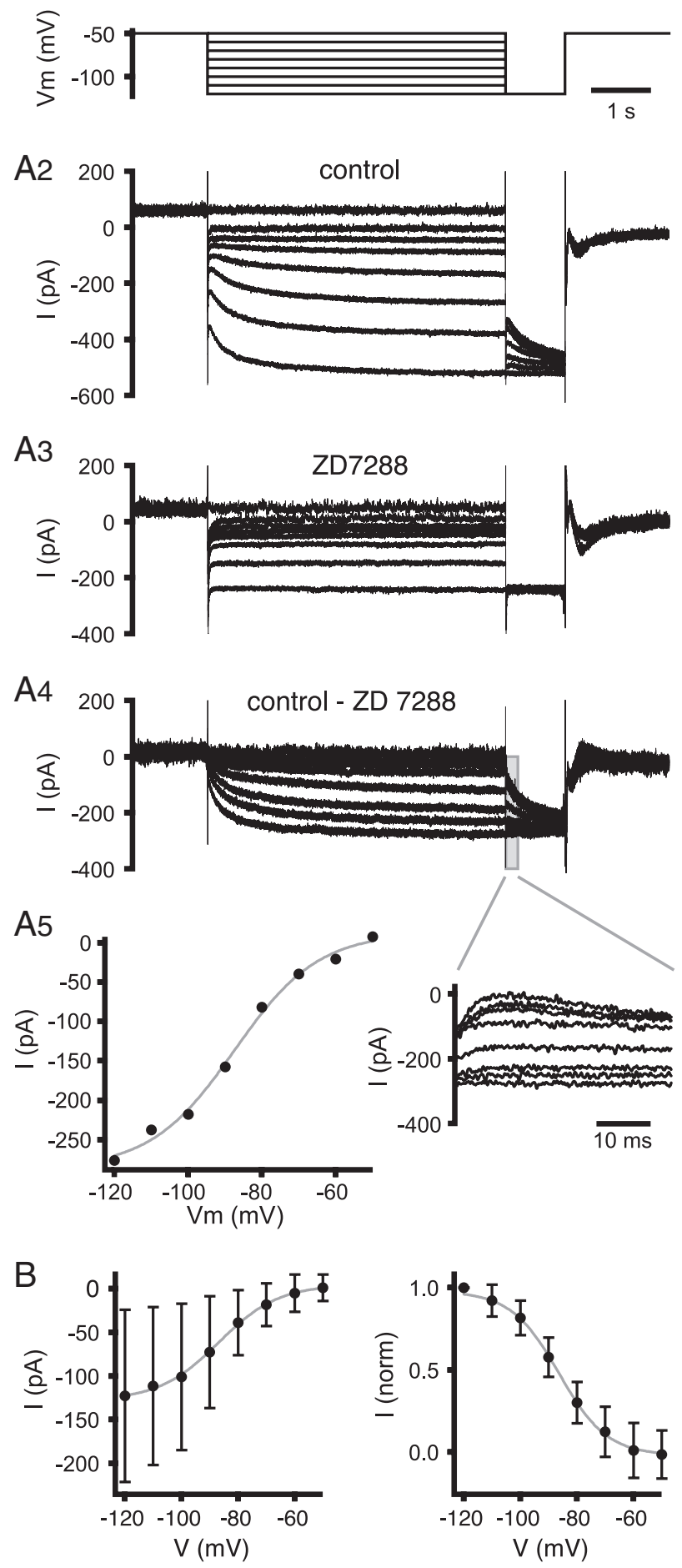

Figure 4. Voltage dependence of HCN channel activation. $\boldsymbol{A}$, Representative example. A1, Voltage-clamp waveform used to measure voltage dependence of $\mathrm{HCN}$ channel activation. A2-A4, Currents measured under control conditions (A2) and in the presence of ZD7288 (A3) and ZD7288-sensitive currents (A4) (inset shows tail currents evoked at $-120 \mathrm{mV}$ ). $\mathbf{A 5}$, ZD7288-sensitive tail currents increased with progressive hyperpolarization from $-60 \mathrm{mV} . \boldsymbol{B}$, Absolute and normalized (norm) ZD7288-sensitive tail currents for the sample population. Vm, Membrane potential.

stimulated GP-STN axon (Fig. 5). Minimal stimulation was performed as described previously (Baufreton et al., 2009). The temporal pattern of minimal stimulation was derived from a GP neuron recorded extracellularly in an awake restrained rat 
$\mathrm{A} 1$
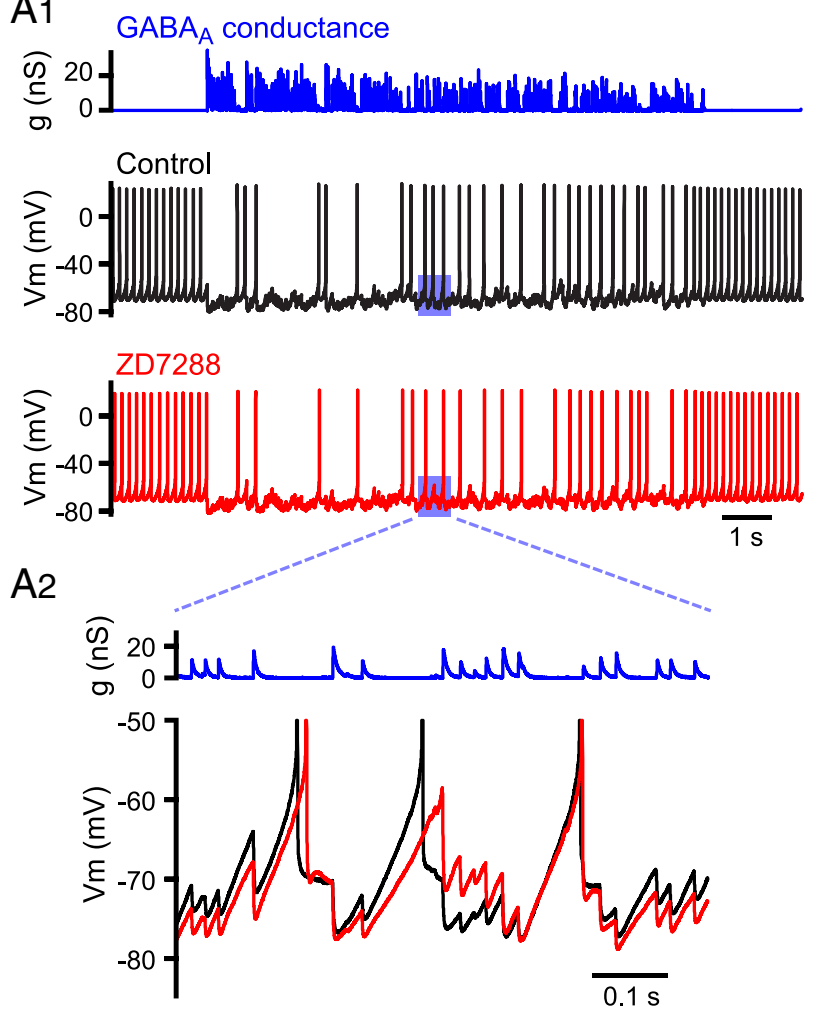

B
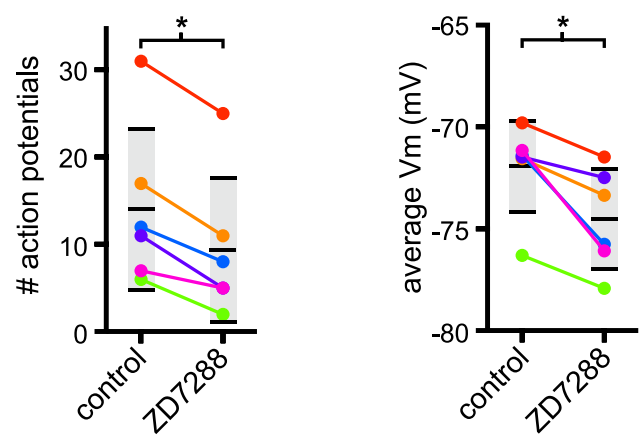

Figure 5. The impact of $\mathrm{GABA}_{\mathrm{A}}$ receptor-mediated inhibition is enhanced by blockade of HCN channels. A1, Response of a STN neuron under control conditions (black) and in the presence of $Z D 7288$ (red) to an in vivo-like $G_{A B A}$ receptor-mediated synaptic conductance waveform (blue). A2, Zoom of epoch highlighted by blue rectangle in $\boldsymbol{A}$ 1. Blockade of HCN channels increased inhibition of autonomously generated action potentials (control example 31 action potentials; ZD7288 example 25 action potentials) and the degree of hyperpolarization produced by the $\mathrm{GABA}_{\mathrm{A}}$ receptor-mediated synaptic conductance in both the representative example $(\boldsymbol{A})$ and the sample population ( $\boldsymbol{B}$; individual cells denoted by distinct colors; sample mean and SD also indicated). Vm, Membrane potential; ${ }^{*} p<0.05$.

(Urbain et al., 2000). The record was chosen because the frequency and pattern of activity of the GP neuron was close to the population mean (frequency $=33 \mathrm{~Hz} ; \mathrm{CV}=0.65$ ). Application of ZD7288 significantly reduced the number of action potentials generated (control $=14.0 \pm 9.2 ; \mathrm{ZD} 7288=9.3 \pm 8.3 ; n=6$; WSR test, $p<0.05$ ) and significantly hyperpolarized the membrane potential (control $=-71.9 \pm 2.2 \mathrm{mV}$; ZD7288 $=-74.5 \pm$ $2.5 \mathrm{mV} ; n=6$; WSR test, $p<0.05$ ) during the period of conductance injection. Both the peak and decay time course of IPSPs were clearly increased by blockade of HCN channels. Similar results were also obtained when $\mathrm{HCN}$ channels were blocked with $2 \mathrm{~mm} \mathrm{Cs}^{+}$in each of three neurons tested (action potentials: control $\left.=29.0 \pm 14.0 ; \mathrm{Cs}^{+}=18.7 \pm 10.1 ; n=3\right)\left(V_{\mathrm{m}}\right.$ : control $=$ $\left.-71.2 \pm 3.2 \mathrm{mV} ; \mathrm{Cs}^{+}=-73.5 \pm 3.1 \mathrm{mV}\right)$.
To determine how the distribution of HCN channels might influence the integration of inhibitory inputs across the somatodendritic axis, the effect of the same inhibitory conductance waveform was analyzed for models in which HCN channel conductance was present at the soma or across the somatodendritic axis or was absent. The inhibitory conductance waveform was applied to the soma (supplemental Fig. S1, available at www. jneurosci.org as supplemental material) or most distal dendritic compartment (Fig. 6). In either case, the somatodendritic model was associated with greater spiking activity and was slightly more depolarized than the somatic model (somatic conductance injection: somatic HCN model: spikes $=59$, mean $V_{0}=-71.0 \mathrm{mV}$, mean $V_{4}=-69.9 \mathrm{mV}$; somatodendritic $\mathrm{HCN}$ model: spikes $=$ 65 , mean $V_{0}=-70.7 \mathrm{mV}$, mean $V_{4}=-69.2 \mathrm{mV}$; dendritic conductance injection: somatic HCN model: spikes $=41$, mean $V_{0}=-67.8 \mathrm{mV}$, mean $V_{4}=-72.7 \mathrm{mV}$; somatodendritic $\mathrm{HCN}$ model: spikes $=54$, mean $V_{0}=-67.4 \mathrm{mV}$, mean $V_{4}=-71.9$ $\mathrm{mV})$. As predicted, the deficient model was relatively inhibited and more hyperpolarized than either of the models expressing HCN channels (somatic conductance injection: HCN-deficient model: spikes $=51$, mean $V_{0}=-71.8 \mathrm{mV}$, mean $V_{4}=-70.6$ $\mathrm{mV}$; dendritic conductance injection: $\mathrm{HCN}$-deficient model: spikes $=30$, mean $V_{0}=-68.6 \mathrm{mV}$, mean $V_{4}=-73.1 \mathrm{mV}$ ).

To determine how HCN channels interact with other channels to oppose synaptic inhibition and promote action potential generation, the magnitude of $\mathrm{HCN}, \mathrm{Na}_{\mathrm{v}}$, and $\mathrm{Ca}_{\mathrm{v}} 3$ channel currents were compared for each model during the somatic (supplemental Fig. S1 $B$, available at www.jneurosci.org as supplemental material) or dendritic (Fig. 6B) application of the $\mathrm{GABA}_{\mathrm{A}}$ receptor-mediated inhibitory conductance. In each case, the somatodendritic model was associated with larger depolarizing $\mathrm{Na}_{\mathrm{v}}$ and $\mathrm{HCN}$ channel currents than the somatic model and similar $\mathrm{Ca}_{\mathrm{v}} 3$ channel currents (somatic conductance injection: somatic model: $I_{\mathrm{Nav}}=-17.0 \mathrm{pA}, I_{\mathrm{HCN}}=-2.0 \mathrm{pA}, I_{\mathrm{Cav} 3}=-3.7 \mathrm{pA}$; somatodendritic model: $I_{\mathrm{Nav}}=-18.5 \mathrm{pA}, I_{\mathrm{HCN}}=-2.8 \mathrm{pA}$, $I_{\text {Cav3 }}=-3.8 \mathrm{pA}$; dendritic conductance injection: somatic mod$\mathrm{el}: I_{\mathrm{Nav}}=-14.6 \mathrm{pA}, I_{\mathrm{HCN}}=-1.3 \mathrm{pA}, I_{\mathrm{Cav} 3}=-2.4 \mathrm{pA}$; somatodendritic model: $I_{\mathrm{Nav}}=-17.7 \mathrm{pA}, I_{\mathrm{HCN}}=-2.7 \mathrm{pA}, I_{\mathrm{Cav} 3}=-2.4$ pA). $\mathrm{Na}_{\mathrm{v}}$ and, to a lesser extent, $\mathrm{Ca}_{\mathrm{v}} 3$ channel current were also smallest for the HCN-deficient model, presumably due to weaker activation of the channels at the relatively hyperpolarized voltages associated with the HCN-deficient model (somatic conductance injection: deficient model: $I_{\mathrm{Nav}}=-14.9 \mathrm{pA}, I_{\mathrm{HCN}}=0 \mathrm{pA}$, $I_{\text {Cav3 }}=-3.5 \mathrm{pA}$; dendritic conductance injection: deficient model: $\left.I_{\mathrm{Nav}}=-11.5 \mathrm{pA}, I_{\mathrm{HCN}}=0 \mathrm{pA}, I_{\mathrm{Cav} 3}=-2.3 \mathrm{pA}\right)$.

One reason for larger HCN channel current in the somatodendritic model appears to be the effect of action potentials, which more effectively reduce the electrochemical gradient for HCN channel current and deactivate somatic compared to dendritic HCN channels. The effect on HCN channel current was further augmented by the slow kinetics of HCN channel activation following spike-generated deactivation (supplemental Fig. $\mathrm{S} 1 B$, available at www.jneurosci.org as supplemental material). Indeed, when backpropagation of action potentials into dendritic compartments was enhanced by increasing dendritic $\mathrm{Na}_{\mathrm{v}}$ channel conductance from 0.01 to $1.0 \mathrm{mS} \cdot \mathrm{cm}^{-2}$ in each dendritic compartment (while reducing somatic conductance to $28 \mathrm{mS} \cdot \mathrm{cm}^{-2}$ to maintain the same whole-cell $\mathrm{Na}_{\mathrm{v}}$ channel conductance), the relative capability of the somatodendritic model compared to the somatic model to counteract inhibition was eliminated (somatic conductance injection: somatic HCN model: spikes $=54$, mean $V_{0}=-70.9 \mathrm{mV}$, mean $V_{4}=-69.2 \mathrm{mV}$; somatodendritic HCN model: spikes $=54$, mean $V_{0}=-71.0 \mathrm{mV}$, mean $V_{4}=-69.1$ 

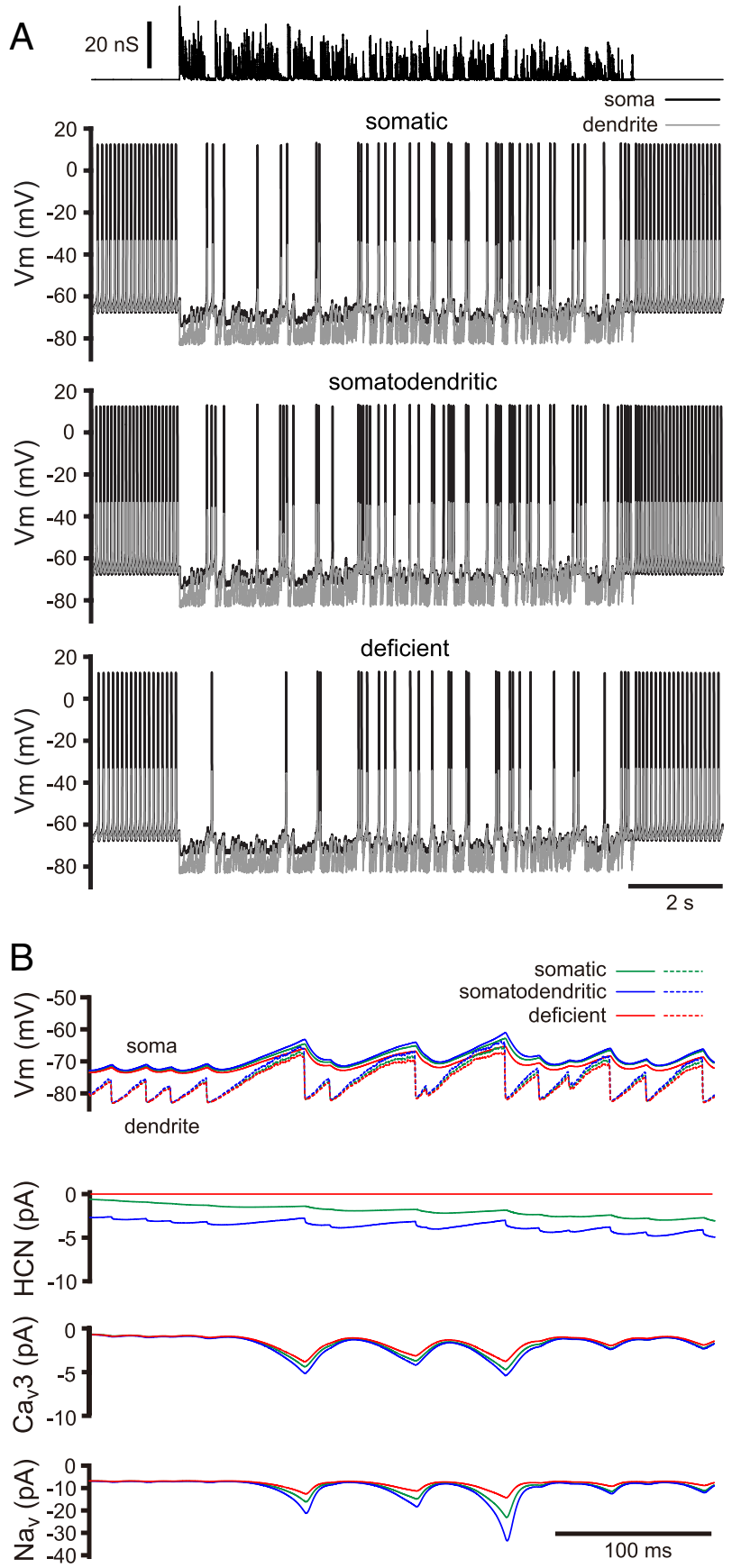

Figure 6. HCN channels distributed across the somatodendritic axis most effectively counteract GABAergic inhibition. $\boldsymbol{A}$, Somatic (black) and fourth (most distal) dendritic compartment (gray) responses of each STN neuron model to a $G A B A_{A}$ receptor-mediatedsynaptic conductance (top) applied to the fourth dendritic compartment. The number of action potentials generated during GABAergic inhibition was 41, 54, and 30 for the somatic, somatodendritic, and deficient models, respectively. $\boldsymbol{B}$, Zoom of the epoch 2-2.4 s from the traces in $\boldsymbol{A}$. During the period of inhibition the somatic and fourth dendritic compartments of the somatodendritic model (blue) were relatively depolarized compared to the somatic (green) and deficient (red) models. Whole-cell $\mathrm{HCN}$ and $\mathrm{Na}_{\mathrm{v}}$ channel currents were also greatest for the somatodendritic model. Vm, Membrane potential.

$\mathrm{mV}$; dendritic conductance injection: somatic HCN model: spikes $=36$, mean $V_{0}=-67.8 \mathrm{mV}$, mean $V_{4}=-72.2 \mathrm{mV}$; somatodendritic HCN model: spikes $=36$, mean $V_{0}=-67.8$ $\mathrm{mV}$, mean $V_{4}=-72.0 \mathrm{mV}$ ). However, the relative susceptibility of the HCN-deficient model to inhibition was not abolished (somatic conductance injection: $\mathrm{HCN}$-deficient model: spikes $=47$, mean $V_{0}=-71.7 \mathrm{mV}$, mean $V_{4}=-70.0 \mathrm{mV}$; dendritic conductance injection: $\mathrm{HCN}$-deficient model: spikes $=26$, mean $V_{0}=$ $-68.7 \mathrm{mV}$, mean $V_{4}=-72.8 \mathrm{mV}$ ).

To further address the robustness of $\mathrm{HCN}$ channel placement effects, (1) whole-cell HCN channel and applied $\mathrm{GABA}_{\mathrm{A}}$ receptor inhibitory conductances were decreased and increased by an order of magnitude, and (2) the input resistance of each model was halved to $350 \mathrm{M} \Omega$ by increasing leak conductance from 0.08 to $0.12 \mathrm{mS} \cdot \mathrm{cm}^{-2}$. All other conductances were then scaled similarly to compensate for reduced excitability. The trends observed in the original simulations were robust for a wide range of parameters (supplemental Tables S1, S2, available at www.jneurosci.org as supplemental material). Furthermore, the effects of HCN channel expression and somatodendritic placement were enhanced as $\mathrm{GABA}_{\mathrm{A}}$ receptor and/or $\mathrm{HCN}$ channel conductance was increased and/or input resistance decreased. Together the data demonstrate that (1) HCN channels distributed throughout the somatodendritic compartment (similar to the distribution observed experimentally) most effectively opposed synaptic inhibition directed to the somatic or dendritic compartment and (2) the relative capability of somatodendritic $\mathrm{HCN}$ channels to counteract inhibition was associated with larger $\mathrm{Na}_{\mathrm{v}}$ and $\mathrm{HCN}$ channel currents.

\section{$\mathrm{HCN}$ channels limit the deinactivation of $\mathrm{Ca}_{\mathrm{v}} 3$ channels in STN neurons}

Several studies suggest that HCN channels play a pivotal role in the regulation of $\mathrm{Ca}_{\mathrm{v}}$ channel-mediated electrogenesis (Pape and McCormick, 1989; Lüthi and McCormick, 1998; Kole et al., 2007; Tsay et al., 2007). In STN neurons, hyperpolarization below the voltages associated with autonomous activity can lead to the deinactivation of $\mathrm{Ca}_{\mathrm{v}} 3$ and other low-voltage-activated $\mathrm{Ca}^{2+}$ channels, which at the offset of hyperpolarization can underlie rebound burst activity (Beurrier et al., 1999; Bevan and Wilson, 1999; Otsuka et al., 2001; Bevan et al., 2002; Hallworth et al., 2003; Hallworth and Bevan, 2005; Kass and Mintz, 2006). We hypothesized that by opposing hyperpolarization, $\mathrm{HCN}$ channels limit deinactivation of $\mathrm{Ca}_{\mathrm{v}} 3$ and other low-voltage-activated $\mathrm{Ca}^{2+}$ channels and thus the propensity for rebound burst firing.

The response of STN neurons to the offset of 500 ms moderate hyperpolarizing current under control conditions and in the presence of ZD7288 was characterized (Fig. 7). Rebound activity was compared for both matching voltage at the end of the current step (approximately $-85 \mathrm{mV}$ ) and matching hyperpolarizing current (approximately $-15 \mathrm{pA}$ ). The latency to the generation of the first action potential following the offset of hyperpolarizing current was greatly increased for both comparisons following blockade of HCN channels (Fig. 7) (latency following $-15 \mathrm{pA}$ injection: control $=85.5 \pm 16.9 \mathrm{~ms}$; ZD7288 $=364.4 \pm 342.3$ ms; $n=6$; WSR test, $p<0.05$; latency following hyperpolarization to $-85 \mathrm{mV}$ : control $=57.1 \pm 23.6 \mathrm{~ms}$; ZD7288 $=364.4 \pm$ $342.3 \mathrm{~ms} ; n=6$; WSR test, $p<0.05$ ). The duration and frequency of rebound activity, defined as activity exceeding the mean autonomous firing frequency $+3 \mathrm{SD}$, was also significantly increased by ZD7288 for matching current (Fig. 7) (duration of rebound activity following $-15 \mathrm{pA}$ injection: control $=453.6 \pm$ $461.4 \mathrm{~ms} ; \mathrm{ZD} 7288=1537.6 \pm 990.1 \mathrm{~ms} ; n=6$; WSR test, $p<$ 0.05 ; maximum frequency of rebound activity following $-15 \mathrm{pA}$ injection: control $=30.9 \pm 47.8 \mathrm{~Hz}$; ZD7288 $=98.3 \pm 61.4 \mathrm{~Hz}$; $n=6$; WSR test, $p<0.05$; mean frequency of rebound activity following $-15 \mathrm{pA}$ injection: control $=14.6 \pm 17.4 \mathrm{~Hz}$; ZD7288 = 38.1 $\pm 26.1 \mathrm{~Hz} ; n=6$; WSR test, $p<0.05$ ) but not for voltage (data not shown). Rebound activity following the termi- 
A1
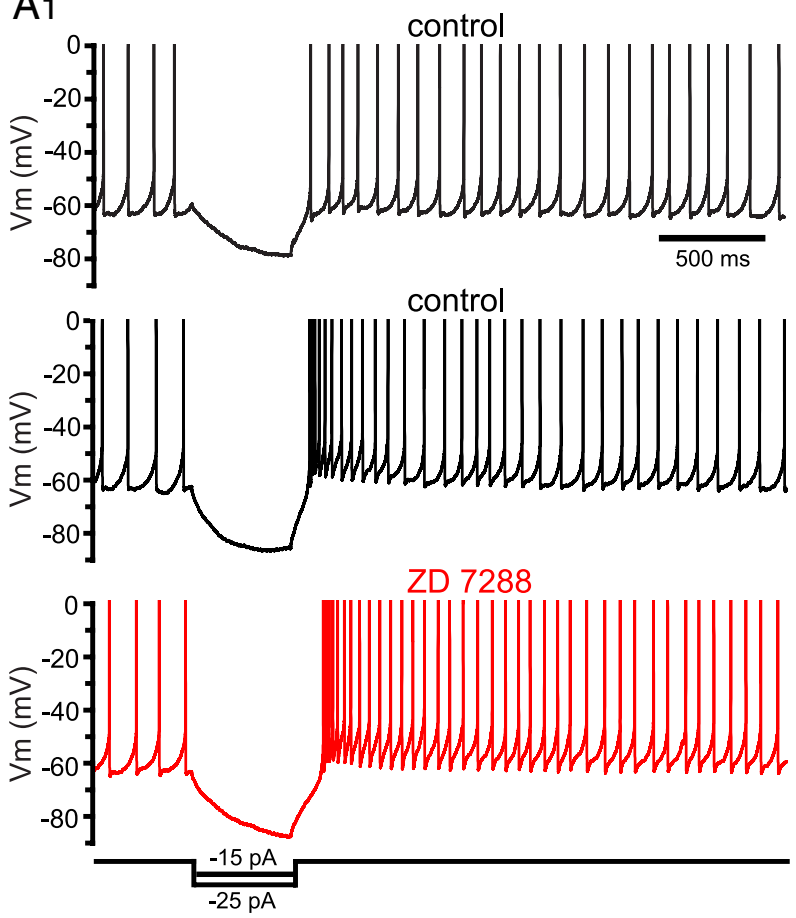

A2

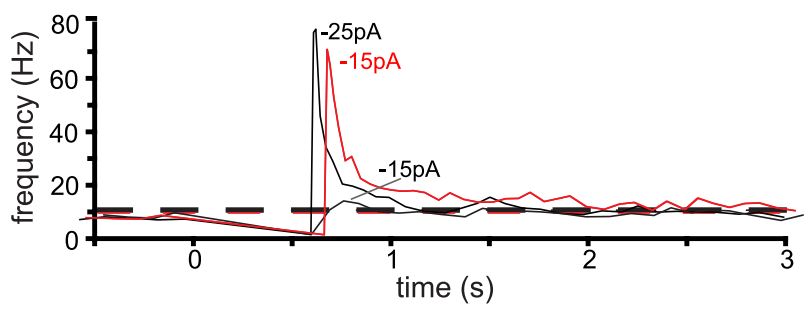

B
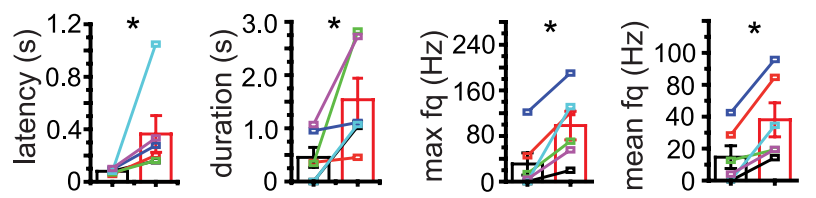

Figure 7. Blockade of HCN channels increases the intensity of rebound burst firing. $\boldsymbol{A}, \mathrm{Re}-$ sponse of a STN neuron under control conditions (black) and in the presence of ZD7288 (red) to hyperpolarizing current injection. $\boldsymbol{A 1}$, From top to bottom, responses to $-15 \mathrm{pA},-25 \mathrm{pA}$, and $-15 \mathrm{pA}$, respectively. $\mathbf{A 2}$, Instantaneous frequency plots for each trace. Dashed line represents the mean instantaneous frequency $+3 S D$ associated with autonomous activity. The degree of hyperpolarization and frequency of subsequent rebound activity in response to $-15 \mathrm{pA}$ were greatly enhanced by ZD7288. Application of $-25 \mathrm{pA}$ and $-15 \mathrm{pA}$ under control conditions and in the presence of ZD7288 produced similar degrees of hyperpolarization and rebound activity, respectively. $\boldsymbol{B}$, Population data. Individual cells are represented by distinct colors. Population mean and SD are also indicated. Action potentials truncated at $0 \mathrm{mV} ; \mathrm{fq}$, frequency; $\mathrm{Vm}$, membrane potential; ${ }^{*} p<0.05$.

nation of -15 pA current injection was also delayed (control $=$ $\left.244.7 \pm 72.8 \mathrm{~ms} ; \mathrm{Cs}^{+}=360.0 \pm 44.9 \mathrm{~ms} ; n=4\right)$ but enhanced in intensity (maximum frequency: control $=7.8 \pm 10.4 \mathrm{~Hz} \mathrm{Cs}^{+}=$ $92.4 \pm 39.3 \mathrm{~Hz} ; n=4$; mean frequency: control $=7.8 \pm 9.9 \mathrm{~Hz}$; $\mathrm{Cs}^{+}=34.2 \pm 4.6 \mathrm{~Hz} ; n=4$ ) and duration (control $=138.9 \pm$ $173.2 \mathrm{~ms} ; \mathrm{Cs}^{+}=2553.0 \pm 3306 \mathrm{~ms} ; n=4$ ) by application of 2 $\mathrm{mM} \mathrm{Cs}^{+}$in a manner similar to that produced by ZD7288 in each of four neurons tested. Together these data confirm that HCN channels accelerate depolarization following the offset of hyperpolarizing current and by restricting hyperpolarization during current application reduce the intensity of rebound burst activity.
To isolate the action of HCN channels on the availability of $\mathrm{Ca}_{\mathrm{v}} 3$ and other low-voltage-activated $\mathrm{Ca}^{2+}$ channels, the response of STN neurons to hyperpolarization was studied in the presence of TTX to block $\mathrm{Na}_{\mathrm{v}}$ channels (and thus minimize recruitment of high-voltage-activated $\mathrm{Ca}^{2+}$ channels) and with 2PLSM imaging of the $\mathrm{Ca}^{2+}$ indicator dye fluo-4 to determine the magnitude of $\mathrm{Ca}^{2+}$ channel-mediated electrogenesis in STN neuron dendrites. Blockade of HCN channels significantly increased the magnitude of rebound depolarization following the offset of $-20 \mathrm{pA}$ to $-30 \mathrm{pA}$ current injection [integral of rebound depolarization $(\mathrm{mV} \cdot \mathrm{s})$ : control $=3.55 \pm 3.59$; ZD7288 $=12.89 \pm 7.98 ; n=6$; WSR test, $p<0.05$ ], which in turn was associated with an increase in the integral of rebound $\mathrm{Ca}^{2+}$ entry (Fig. 8A) [integral of rebound $\mathrm{Ca}^{2+}\left(\Delta G / R_{0} \cdot \mathrm{s}\right)$ : control $=0.14 \pm 0.08 ; \mathrm{ZD} 7288=0.35 \pm 0.28 ; n=6$; WSR test, $p<$ 0.05]. Blockade of HCN channels with ZD7288 similarly increased the magnitude of rebound depolarization [integral of rebound depolarization $(\mathrm{mV} \cdot \mathrm{s})$ : control $=10.10 \pm 3.76$; ZD7288 $=17.49 \pm 5.87 ; n=6]$ and associated rebound $\mathrm{Ca}^{2+}$ entry [integral of rebound $\mathrm{Ca}^{2+}\left(\Delta G / R_{0} \cdot \mathrm{s}\right)$ : control $=0.15 \pm$ 0.03 ; ZD7288 $=0.25 \pm 0.05 ; n=6$; WSR test, $p<0.05$ ] when a $\mathrm{GABA}_{\mathrm{A}}$ conductance waveform (peak $35 \mathrm{nS}$ ) was used in place of current to generate hyperpolarization (Fig. $8 B$ ). Similar effects were observed when HCN channels were blocked with $2 \mathrm{~mm} \mathrm{Cs}^{+}$ in place of ZD7288 in each of three neurons injected with the $\mathrm{GABA}_{\mathrm{A}}$ conductance waveform [integral of rebound depolarization $(\mathrm{mV} \cdot \mathrm{s})$ : control $=4.69 \pm 9.89 ; \mathrm{Cs}^{+}=12.02 \pm 9.89 ; n=3$; integral of rebound $\mathrm{Ca}^{2+}\left(\Delta G / R_{0} \cdot \mathrm{s}\right)$ : control $=0.08 \pm 0.02$; $\left.\mathrm{Cs}^{+}=0.18 \pm 0.08 ; n=3\right]$.

To determine the impact of HCN channels on the specific contribution of $\mathrm{Ca}_{\mathrm{v}} 3$ channels, a synaptic $\mathrm{GABA}_{\mathrm{A}}$ receptor conductance (peak conductance of $80 \mathrm{nS}$ at $40 \mathrm{~Hz}$ for $5 \mathrm{~s}$ ) was applied to the soma of the original somatic, somatodendritic, and deficient models and the $\mathrm{Ca}_{\mathrm{v}} 3$ channel conductance following the termination of inhibition was studied (Fig. 9; supplemental Table S3, available at www.jneurosci.org as supplemental material). A range of hypothetical $\mathrm{Ca}_{\mathrm{v}} 3$ channel conductances (original and $2-5 \times$ original) were incorporated into each model to more fully explore the interactions. Simulations supported experimental observations that deficiency of HCN channels causes GABAergic inhibition to more effectively hyperpolarize STN neurons, which in turn leads to more complete deinactivation of $\mathrm{Ca}_{\mathrm{v}} 3$ channels and thus relatively powerful $\mathrm{Ca}_{\mathrm{v}} 3$ channel-mediated rebound burst firing at the offset of inhibition (Fig. 9; supplemental Table S3, available at www.jneurosci.org as supplemental material). This effect was amplified by increasing $\mathrm{Ca}_{\mathrm{v}} 3$ channel conductance. Together, the experimental and modeling data suggest that STN HCN channels limit the capability of $\mathrm{GABA}_{\mathrm{A}}$-receptormediated inhibition to generate low-voltage-activated $\mathrm{Ca}^{2+}$ channel-mediated rebound burst firing in STN neurons.

\section{Glutamatergic excitation is enhanced by blockade of $\mathrm{HCN}$ channels in a voltage-dependent manner}

HCN channels have also been shown to play a critical role in the integration of dendritic excitatory glutamatergic synaptic inputs in a variety of neurons by reducing the amplitude and time course of EPSPs and thus the probability of temporal summation (Magee, 1998, 1999; Williams and Stuart, 2000; Williams et al., 2003; Angelo et al., 2007; Bullis et al., 2007). To determine whether HCN channels play a similar role in STN neurons, their responses to $2 \mathrm{PLU}$ of MNI-glutamate ( $0.5 \mathrm{~ms}$ duration) at three adjacent dendritic spine-like structures ( $50 \mathrm{~ms}$ interval between uncaging at each site) were compared under control conditions 

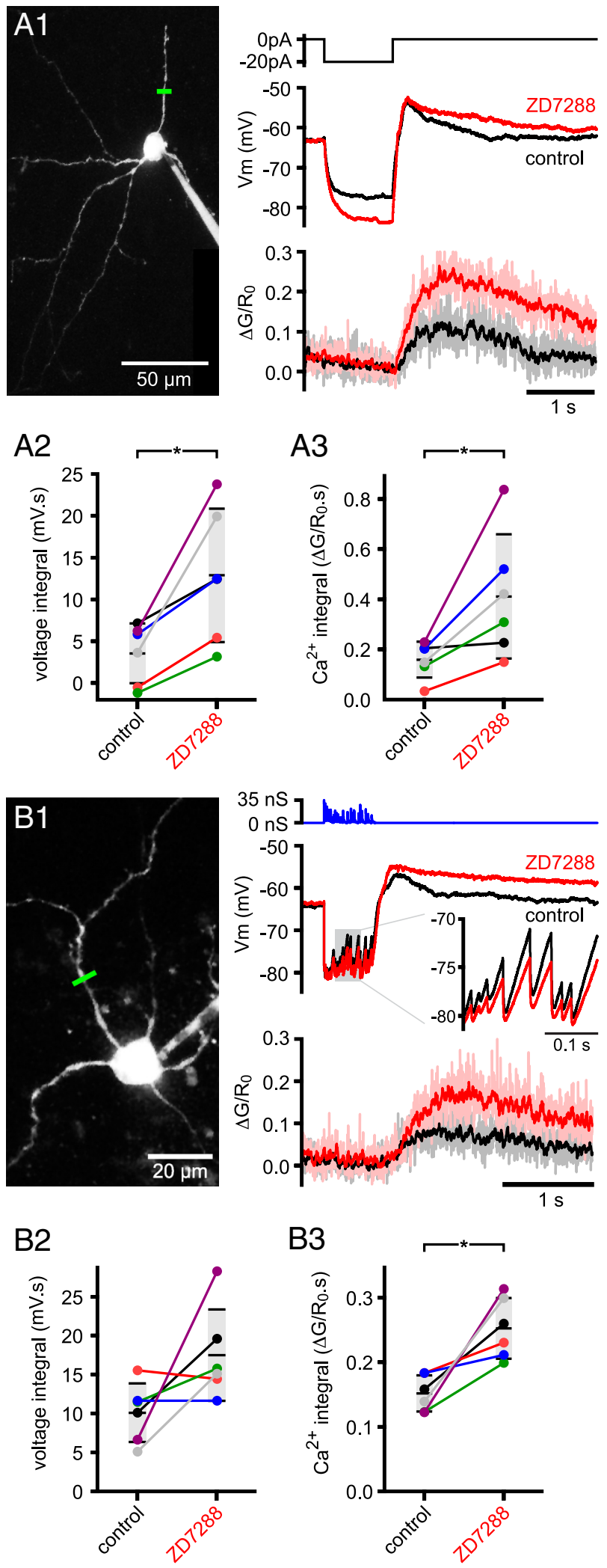

Figure 8. Blockade of HCN channels increases rebound activity of low-voltage-activated $\mathrm{Ca}^{2+}$ channels. A1, Left panel, 2PLSM image of a STN neuron with the site of a dendritic line scan indicated (green bar); right panel, voltage and $\mathrm{Ca}^{2+}$ indicator response to hyperpolarizing current injection under control conditions (black) and in the presence of ZD7288 (red). A2, A3, Population data. Individual cells denoted by distinct colors. Mean and SD are indicated. Rebound depolarization and rebound $\mathrm{Ca}^{2+}$ entry were enhanced by ZD7288. B1, Left panel, 2PLSM image of a STN neuron with the site of a dendritic line scan indicated (green bar); right
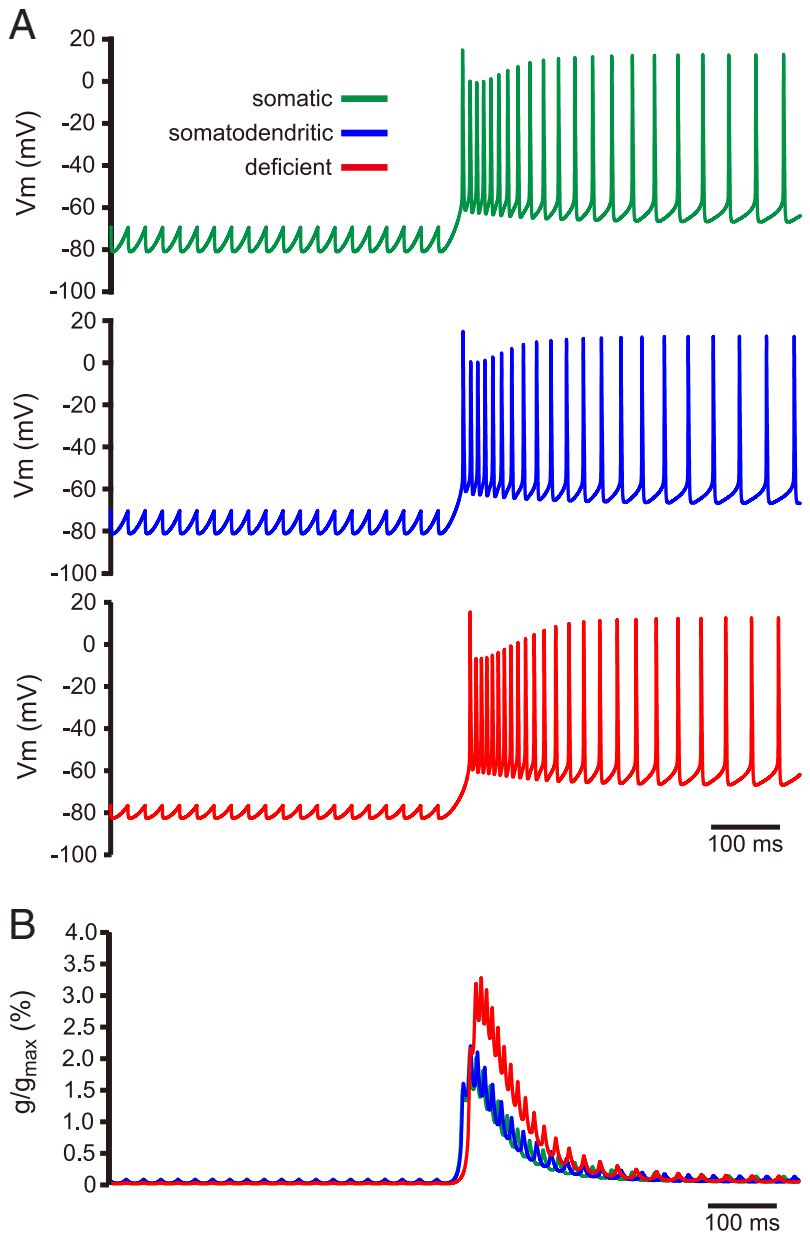

Figure 9. $\mathrm{HCN}$ channels reduce the propensity for $\mathrm{Ca}_{v} 3$ channel-mediated rebound burst firing. $A$, Somatic responses of the somatic, somatodendritic, and deficient STN HCN models at the end and offset of somatic $G A B A_{A}$ receptor synaptic conductance injection. The effectiveness of $G A B A_{A}$ receptor-mediated hyperpolarization and subsequent rebound burst firing is enhanced by deficiency of $\mathrm{HCN}$ channels. $\boldsymbol{B}$, Conductance (expressed as $\% g / g_{\max }$ ) of (a 3 channels for the three models at the end and offset of somatic $\mathrm{GABA}_{A}$ receptor synaptic conductance injection. During inhibition the conductance of $\mathrm{Ca}_{v} 3$ channels is smallest in the $\mathrm{HCN}$-deficient model. At the offset of inhibition the conductance of $\mathrm{Ca}_{\mathrm{v}} 3$ channels is largest in the $\mathrm{HCN}$ deficient model. Vm, Membrane potential.

and in the presence of ZD7288. Uncaging was performed in two voltage ranges at approximately $-70 \mathrm{mV}$, i.e., the most hyperpolarized point of autonomous oscillation, and at approximately $-80 \mathrm{mV}$, i.e., close to equilibrium potential of $\mathrm{GABA}_{\mathrm{A}}$ receptor current. Voltage was controlled by application of hyperpolarizing current $1 \mathrm{~s}$ before uncaging. The selective $\mathrm{Na}_{\mathrm{v}}$ channel blocker TTX was used in experiments where neurons were held at -70 $\mathrm{mV}$ to improve voltage control. TTX was not applied to neurons held at $-80 \mathrm{mV}$. 2PLU EPSPs were relatively sensitive to application of an AMPA receptor antagonist compared to an NMDA receptor antagonist $[\mathrm{EPSP}$ integral $(\mathrm{mV} \cdot \mathrm{s})$ : control $=0.23 \pm$ 0.14 ; DNQX $=0.09 \pm 0.09 ; n=6$; WSR test, $p<0.05$; for APV:

panel, voltage and $\mathrm{Ca}^{2+}$ indicator response to $\mathrm{GABA}_{\mathrm{A}}$ receptor conductance injection under control conditions (black) and in the presence ZD7288 (red). The $G_{A B A_{A}}$ receptor conductance more effectively hyperpolarizes the membrane potential following blockade of HCN channels. $B 2, B 3$, Population data. Individual cells denoted by distinct colors. Mean and SD are indicated. Rebound depolarization and rebound $\mathrm{Ca}^{2+}$ entry were enhanced by application of ZD7288. $V m$, Membrane potential; ${ }^{*} p<0.05$. 

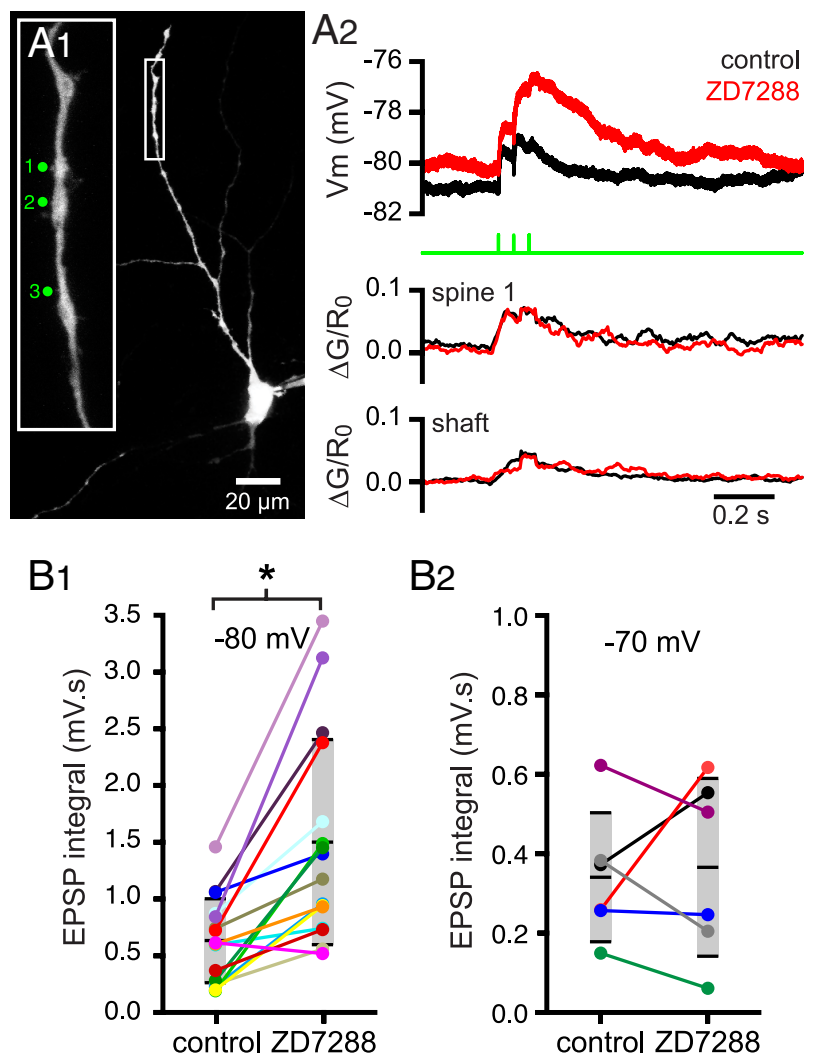

B2

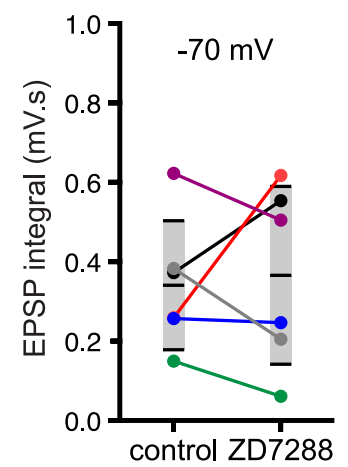

Figure 10. Glutamatergic excitation is enhanced by blockade of HCN channels in a voltagedependent manner. A1, 2PLSM image of a STN neuron together with sites of 2PLU of MNIglutamate (1-3). A2, Somatic compound EPSPs generated at approximately $-80 \mathrm{mV}$ by $2 \mathrm{PLU}$ of MNl-glutamate (green) and associated $\mathrm{Ca}^{2+}$ dynamics at spine 1 and underlying dendritic shaft under control conditions (black) and in the presence of ZD7288 (red). The somatic EPSP was amplified by blockade of HCN channels, but associated $\mathrm{Ca}^{2+}$ dynamics were unaltered. $\boldsymbol{B}$, Population data. Individual cells denoted by distinct colors. Mean and SD are indicated. The somatic EPSP integral generated at $-80 \mathrm{mV}$ and $-70 \mathrm{mV}$ by 2PLU of MNI-glutamate was enhanced and unaltered by application of ZD7288, respectively. Vm, Membrane potential; ${ }^{*} p<0.05$.

control $=0.42 \pm 0.19 ; \mathrm{APV}=0.30 \pm 0.25 ; n=6$; WSR test, N.S.]. Application of ZD7288 significantly increased the compound EPSP integral at $-80 \mathrm{mV}$ (Fig. 10) (control $=0.63 \pm 0.37$; ZD7288 $=1.50 \pm 0.90 ; n=16$; WSR test, $p<0.05)$ but had no apparent effect at $-70 \mathrm{mV}$ (Fig. 10) (control =0.34 \pm 0.16 ; ZD7288 $=0.37 \pm 0.22 ; n=6$; WSR test, N.S.). The increase in temporal summation at $-80 \mathrm{mV}$ was apparently due to an increase in peak amplitude and duration of the decay phase of individual EPSPs (Fig. 10). EPSP amplification at $-80 \mathrm{mV}$ was apparently not due to the recruitment of local regenerative postsynaptic potentials because (1) $\mathrm{Ca}^{2+}$ entry at the site of $2 \mathrm{PLU}$ EPSPs was not altered by ZD7288 application (Fig. 10 A) [integral of $\Delta G / R_{0}\left(\Delta G / R_{0} \cdot \mathrm{s}\right)$; spine: control $=0.016 \pm 0.012$, ZD7288 $=$ $0.009 \pm 0.012$; dendritic shaft: control $=0.007 \pm 0.008$, ZD7288 $=0.002 \pm 0.014 ; n=6$; WSR test, N.S.], and (2) EPSP summation was typically linear or sublinear both under control conditions and in the presence of ZD7288 (supplemental Fig. S2, available at www.jneurosci.org as supplemental material). The action of $\mathrm{HCN}$ channel blockade at $-80 \mathrm{mV}$ but not $-70 \mathrm{mV}$ is therefore consistent with the participation of $\mathrm{HCN}$ channels in excitatory synaptic integration at voltages more hyperpolarized than the oscillation voltage range.
The impact of HCN channels on excitatory synaptic integration is shunted by inhibitory conductances that are required for their activation

As suggested above, $\mathrm{GABA}_{\mathrm{A}}$ receptor-mediated inhibition should lead to the activation of STN HCN channels in vivo. To determine how inhibitory $\mathrm{GABA}_{\mathrm{A}}$ receptor conductances interact with HCN channels and excitatory synaptic inputs, EPSPs were generated by 2PLU of MNI-glutamate (as described above) in neurons that were hyperpolarized by the constant somatic injection of a $12 \mathrm{nS} \mathrm{GABA}$ A receptor conductance to approximately -80 $\mathrm{mV}$. Interestingly, under these conditions application of ZD7288 had no effect on the compound EPSP integral (Fig. 11 A) (control $=0.04 \pm 0.03 \mathrm{mV} \cdot \mathrm{s} ; \mathrm{ZD} 7288=0.05 \pm 0.05 \mathrm{mV} \cdot \mathrm{s} ; n=6$; WSR test, N.S.). The action of HCN channels on excitatory synaptic integration was therefore explored further in the three original STN HCN models described above (Fig. $11 B-D$ ). EPSPs were generated in the most distal dendritic compartment at $50 \mathrm{~ms}$ intervals with underlying maximal AMPA and NMDA receptor conductances of 1 and $5 \mathrm{nS}$, respectively. When somatic current was used to hyperpolarize each model to approximately $-80 \mathrm{mV}$ the somatic integral of EPSPs was greatest in the HCN-deficient model in line with the experimentally observed effects of ZD7288 application (Fig. $11 \mathrm{~B}$ ). When the magnitude of $\mathrm{GABA}_{\mathrm{A}}$ receptor conductance applied to the soma was adjusted so that the membrane potential at which the first EPSP was evoked was approximately $-80 \mathrm{mV}$, the amplitude and integral of EPSPs were also greatest for the $\mathrm{HCN}$-deficient model (Fig. $11 \mathrm{~B}$ ), which required a smaller $\mathrm{GABA}_{\mathrm{A}}$ receptor conductance $(5.05 \mathrm{nS})$ for hyperpolarization to $-80 \mathrm{mV}$ than the $\mathrm{HCN}$-expressing models ( $14.5 \mathrm{nS}$ for the somatic model and $12.3 \mathrm{nS}$ for the somatodendritic model). However, when a $12.3 \mathrm{nS} \mathrm{GABA}_{\mathrm{A}}$ receptor conductance was applied to each model, the integral of the somatic EPSP was similar for each, although the membrane potential of the HCN-deficient model was relatively hyperpolarized by the $\mathrm{GABA}_{\mathrm{A}}$ receptor conductance compared to the somatic and somatodendritic $\mathrm{HCN}$ models (Fig. 11D). Together these data suggest that $\mathrm{GABA}_{\mathrm{A}}$ receptor-mediated inhibition shunts the effect of $\mathrm{HCN}$ channels on EPSP integration.

\section{Discussion}

Cellular and subcellular expression of HCN subunits

Regional mRNA and protein expression studies have shown that the STN is associated with a high level of HCN2 and 3 and lower levels of HCN1 and 4 expression (Monteggia et al., 2000; Santoro et al., 2000; Notomi and Shigemoto, 2004). Using single-cell molecular profiling, we showed that the detection rates of $\mathrm{HCN}$ subunit expression in individual neurons approximated the regional pattern. Thus, individual STN (and other) neurons express a variety of HCN subunits, which could underlie homomeric channels with heterogenous, distinct biophysical properties and/or heteromeric channels with homogenous, intermediate properties (Robinson and Siegelbaum, 2003; Baruscotti and DiFrancesco, 2004; Biel et al., 2009).

Immunocytochemical detection of HCN2 subunits revealed that STN neurons express HCN2 channel subunits across their somatodendritic plasma membrane. However, the sampling approach used here (and in most studies) might fail to detect heterogeneous cellular and/or subcellular expression patterns. Uniform (Angelo et al., 2007), decreasing (Bullis et al., 2007), and increasing (Magee, 1998, 1999; Williams and Stuart, 2000; Lörincz et al., 2002) somatodendritic expression with distance from the soma have been reported in other neurons using highresolution immunoelectron microscopy (Lörincz et al., 2002; 
A1
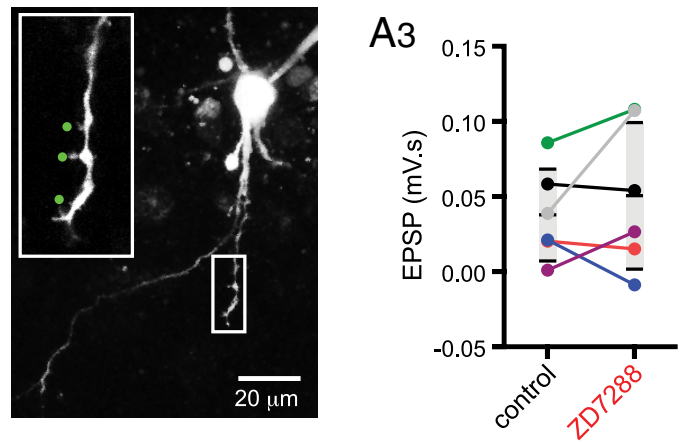

A2

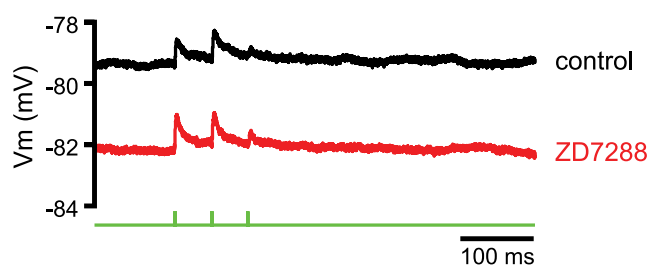

B variable current

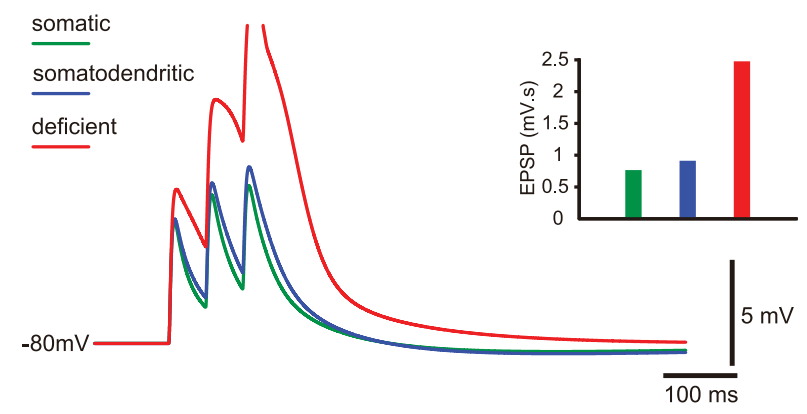

C variable $\mathrm{GABA}_{A} R$ conductance

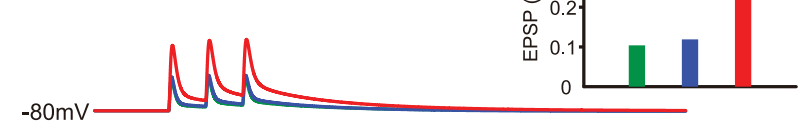

D $\quad 12 n S G A B A_{A} R$ conductance

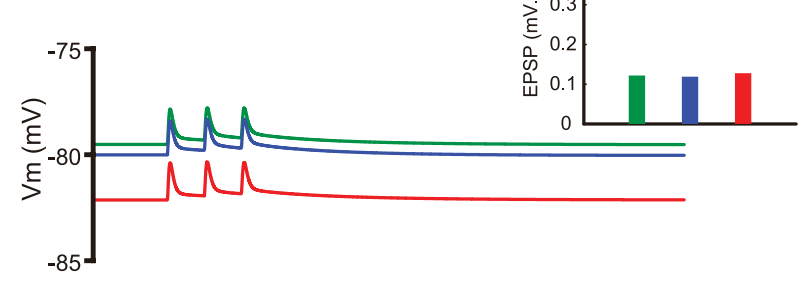

Figure 11. $G A B A_{A}$ receptor-mediated inhibition shunts the effect of $H C N$ channels on excitatory synaptic integration. $\boldsymbol{A} 1,2 \mathrm{PLSM}$ image of a STN neuron together with sites of $2 \mathrm{PLU}$ of MNI-glutamate (green). A2, Somatic compound EPSPs generated by 2PLU of MNI-glutamate (green) during the injection of a $12 \mathrm{nSGABA}$ receptor-mediated conductance under control conditions (black) and in the presence of $Z D 7288$ (red). In the presence of the $\mathrm{GABA}_{\mathrm{A}}$ conductance, blockade of $\mathrm{HCN}$ channels had little effect on the compound EPSP integral either in the example or the sample ( $A 3$; cells denoted by distinct colors; mean and SD indicated). $\boldsymbol{B}-\boldsymbol{D}$, Integration of three excitatory synaptic conductances (AMPA, $1 \mathrm{nS} ;$ NMDA, $5 \mathrm{nS}$ ) delivered to the distal dendritic compartment at 50 ms intervals was analyzed for each STN model under three regimes of inhibition. $\boldsymbol{B}$, Somatic hyperpolarizing current was injected to generate to steady-state somatic hyperpolarization of $-80 \mathrm{mV}$ in each model (somatic, $-57.9 \mathrm{pA}$; somatodendritic, $-49.1 \mathrm{pA}$; deficient, $-20.2 \mathrm{pA}$ ). C, Somatic GABAergic conductances (somatic, $14.5 \mathrm{nS}$; somatodendritic, $12.3 \mathrm{nS}$; deficient, $5.05 \mathrm{nS}$ ) were injected to generate steady-state somatic hyperpolarization of $-80 \mathrm{mV}$. D, An identical somatic GABAergic conductance $(12.3 \mathrm{nS})$ was injected for each model. When the GABAergic conductance was identical EPSP integration was not affected by the presence or absence of $\mathrm{HCN}$ channels although $V_{m}$ was more hyperpolarized in the deficient model. Vm, Membrane potential.
Notomi and Shigemoto, 2004) and/or cell-attached patch-clamp recording (Magee, 1998, 1999; Williams and Stuart, 2000; Angelo et al., 2007; Bullis et al., 2007). In pyramidal cells where both approaches have been applied, the data were concordant, implying that immunocytochemical detection of $\mathrm{HCN}$ channels is highly correlated with functional expression. Distinct compartmental expression patterns of $\mathrm{HCN}$ channels may confer neuron-specific cellular and subcellular computational properties (London and Häusser, 2005), as discussed below.

\section{Voltage dependence and kinetics of STN HCN channels}

To determine the voltage range at which STN HCN channels are activated, the responses of STN neurons to current and voltage steps were compared before and during application of ZD7288 or $\mathrm{Cs}^{+}$. In contrast to other autonomously active [e.g., globus pallidus neurons (Chan et al., 2004) and striatal cholinergic interneurons (Bennett et al., 2000)] and inactive [e.g., cortical pyramidal neurons (Magee, 1998, 1999; Shah et al., 2004; Kole et al., 2007; Tsay et al., 2007)] neurons, STN HCN channels are barely activated at the resting membrane potential and contribute little to their intrinsic activity or excitability. Thus loss of HCN channel function was not accompanied by a reduction in the frequency of spontaneous firing (Bennett et al., 2000; Chan et al., 2004), hyperpolarization (Magee, 1998, 1999; Shah et al., 2004; Kole et al., 2007; Tsay et al., 2007), emergence of bistable states (Williams et al., 2002) or an enhancement in excitability (Magee, 1998, 1999; Shah et al., 2004; Kole et al., 2007; Tsay et al., 2007), as reported for other neurons. Only hyperpolarization below the peak of single-spike afterhyperpolarization activated $\mathrm{HCN}$ channels sufficiently to modify the integrative properties of STN neurons. Furthermore, current-clamp recordings used the perforated-patchclamp technique, which suggests that run down of HCN channel function is unlikely to have contributed to the negligible effect of blockade at depolarized voltages. Thus, our data support earlier studies, which used invasive recording methods (Bevan and Wilson, 1999; Beurrier et al., 2000; Do and Bean, 2003).

Although the half-activation voltage of STN HCN channel current overlaps that reported for homomeric and/or heteromeric $\mathrm{HCN} 1-4$ subunit-containing channels, the slow kinetics of activation are consistent with slower gating homomeric and/or heteromeric channels containing HCN2-4 subunits and inconsistent with more rapidly gating homomeric HCN1 channels (Robinson and Siegelbaum, 2003; Baruscotti and DiFrancesco, 2004; Biel et al., 2009). Finally, although measurement of HCN channel properties were compromised by incomplete voltage control (Williams and Mitchell, 2008), the voltage-dependent contribution of STN HCN channels was apparently similar under current and voltage clamp.

\section{STN HCN channels counteract GABAergic inhibition and} thus oppose low-voltage-activated $\mathrm{Ca}^{2+}$ channel-mediated electrogenesis

Studies that maintained natural chloride homeostasis have shown that $\mathrm{GABA}_{\mathrm{A}}$ receptor-mediated inhibition can hyperpolarize STN neurons $20 \mathrm{mV}$ below the voltage range of autonomous STN activity, which in turn leads to deinactivation of low-voltage-activated $\mathrm{Ca}^{2+}$ channels and rebound burst firing (Bevan et al., 2000, 2002; Hallworth and Bevan, 2005). Using hyperpolarizing current injection or the dynamic-clamp technique to impose physiologically relevant patterns of GABAergic inhibition, we found that blockade of HCN channels greatly enhanced inhibition of autonomous activity, the degree of hyperpolarization, and, thus, the propensity for low-voltage-activated $\mathrm{Ca}^{2+}$ channel-mediated re- 
bound burst firing. Computational modeling revealed that somatodendritic HCN channel expression, similar to that observed experimentally, most effectively counteracted inhibition directed toward either the soma or dendrite. Previous studies have shown that dendritic HCN channels may be positioned to reduce local temporal summation of synaptic potentials and/or local regenerative potentials engaged by synaptic input (Magee, 1998, 1999; Shah et al., 2004; Angelo et al., 2007; Bullis et al., 2007; Kole et al., 2007; Tsay et al., 2007). Our findings further suggest that dendritic HCN channels may be protected from deactivation by backpropagating action potentials compared to somatic channels closer to the initiation site. This protective effect may be particularly critical in STN neurons, which express HCN channels that activate slowly following action potential-driven deactivation. The degree to which action potentials attenuate in the extensive small-caliber dendrites of STN neurons is unknown but may be considerable: (1) dendritic, in contrast to axosomatic, $\mathrm{Na}_{\mathrm{v}}$ channels do not contribute to autonomous firing, implying that their density is relatively low (Atherton et al., 2008); (2) the velocity of backpropagation is slow, implying that it is relatively passive in nature (Atherton et al., 2008); and (3) action potential-associated dendritic $\mathrm{Ca}^{2+}$ transients decline precipitously with distance from the soma, implying that the amplitude of dendritic potentials is small (J. F. Atherton and M. D. Bevan, unpublished observations).

The depolarization produced by $\mathrm{HCN}$ channels was supplemented by increased activation of $\mathrm{Na}_{\mathrm{v}}$ and $\mathrm{Ca}_{\mathrm{v}} 3$ channels. $\mathrm{Na}_{\mathrm{v}}$ channels are the primary driver of autonomous firing in STN neurons (Bevan and Wilson, 1999; Beurrier et al., 2000; Do and Bean, 2003), and although $\mathrm{Ca}_{\mathrm{v}} 3$ channels were largely inactivated, a small fraction of channels may contribute a tiny window current that promotes activity (Dreyfus et al., 2010).

\section{STN HCN channels have minimal impact on excitatory synaptic integration}

Somatic and dendritic HCN channels play a critical role in excitatory synaptic integration (Magee, 1998, 1999; Williams and Stuart, 2000; Ludwig et al., 2003; Shah et al., 2004; Angelo et al., 2007; Bullis et al., 2007; Kole et al., 2007; Tsay et al., 2007). Thus, HCN channels reduce the amplitude and time course of EPSPs by reducing the membrane resistance and time constant and deactivating during EPSPs. Using 2PLU of MNI-glutamate at putative axospinous glutamatergic synapses $\sim 50-150 \mu \mathrm{m}$ from the soma, we confirmed that STN HCN channels participate in excitatory synaptic integration but only when hyperpolarized well below the resting membrane potential. In vivo, the primary source of hyperpolarization is likely to arise from activation of globus pallidusSTN synaptic $\mathrm{GABA}_{\mathrm{A}}$ receptors (Hallworth and Bevan, 2005; Tachibana et al., 2008; Karachi et al., 2009). However, we found that $\mathrm{GABA}_{\mathrm{A}}$ receptor conductance (in contrast to hyperpolarizing current) sufficient to recruit STN HCN channels both under experimental conditions and in simulations powerfully shunted the action of HCN channels on EPSP amplitude and time course. These data suggest that in STN (and perhaps other) neurons, concurrent GABAergic inhibition in vivo overwhelms the participation of $\mathrm{HCN}$ channels in excitatory synaptic integration.

\section{Functional implications}

At rest, tonically active globus pallidus neurons inhibit the somatodendritic domain of STN neurons largely through the synaptic activation of $\mathrm{GABA}_{\mathrm{A}}$ receptors (Hallworth and Bevan, 2005; Tachibana et al., 2008; Baufreton et al., 2009; Karachi et al., 2009). Our data suggest that the compartmental distribution and bio- physical properties of STN HCN channels help to maintain STN neurons in a voltage range where autonomous spiking activity is promoted and low-voltage-activated $\mathrm{Ca}^{2+}$ channels are largely inactivated. By maintaining STN activity, HCN channels may help to prevent involuntary movements that are produced by interruptions in STN activity (Crossman et al., 1984; DeLong, 1990; Wichmann et al., 1994; Baunez et al., 1995). By reducing low-voltage-activated $\mathrm{Ca}^{2+}$ channel-dependent burst firing, STN HCN channels may help to prevent akinesia and bradykinesia that are associated with excessive burst firing, e.g., in Parkinson's disease (Bergman et al., 1994; Magill et al., 2001; Levy et al., 2002; Brown, 2003).

The mechanisms through which the distribution, number, and gating of STN HCN channels are dynamically regulated are unknown, but data from thalamic and cortical neurons suggest that intrinsic homeostatic signaling pathways and neuromodulatory tone are critical for maintenance of normal thalamocortical HCN channel function (Pape and McCormick, 1989; Lüthi and McCormick, 1998; Shah et al., 2004; Fan et al., 2005). We therefore speculate that in movement disorders like Parkinson's disease, aberrant afferent activity together with alterations in dopaminergic neuromodulation (Bergman et al., 1994; François et al., 2000; Raz et al., 2000; Magill et al., 2001; Levy et al., 2002; Brown, 2003; Shen and Johnson, 2005; Baufreton and Bevan, 2008; Ramanathan et al., 2008) could represent conditions for the dysregulation of STN HCN channels and thus the emergence of pathological burst firing in STN neurons.

\section{References}

Afsharpour S (1985) Light microscopic analysis of Golgi-impregnated rat subthalamic neurons. J Comp Neurol 236:1-13.

Angelo K, London M, Christensen SR, Häusser M (2007) Local and global effects of $I_{\mathrm{h}}$ distribution in dendrites of mammalian neurons. J Neurosci 27:8643-8653.

Atherton JF, Wokosin DL, Ramanathan S, Bevan MD (2008) Autonomous initiation and propagation of action potentials in neurons of the subthalamic nucleus. J Physiol 586:5679-5700.

Baruscotti M, DiFrancesco D (2004) Pacemaker channels. Ann N Y Acad Sci 1015:111-121.

Baufreton J, Bevan MD (2008) D2-like dopamine receptor-mediated modulation of activity-dependent plasticity at GABAergic synapses in the subthalamic nucleus. J Physiol 586:2121-2142.

Baufreton J, Atherton JF, Surmeier DJ, Bevan MD (2005) Enhancement of excitatory synaptic integration by GABAergic inhibition in the subthalamic nucleus. J Neurosci 25:8505-8517.

Baufreton J, Kirkham E, Atherton JF, Menard A, Magill PJ, Bolam JP, Bevan MD (2009) Sparse but selective and potent synaptic transmission from the globus pallidus to the subthalamic nucleus. J Neurophysiol 102:532545

Baunez C, Nieoullon A, Amalric M (1995) In a rat model of parkinsonism, lesions of the subthalamic nucleus reverse increases of reaction time but induce a dramatic premature responding deficit. J Neurosci 15:6531-6541.

Bennett BD, Callaway JC, Wilson CJ (2000) Intrinsic membrane properties underlying spontaneous tonic firing in neostriatal cholinergic interneurons. J Neurosci 20:8493-8503.

Bergman H, Wichmann T, Karmon B, DeLong MR (1994) The primate subthalamic nucleus. II. Neuronal activity in the MPTP model of parkinsonism. J Neurophysiol 72:507-520.

Beurrier C, Congar P, Bioulac B, Hammond C (1999) Subthalamic nucleus neurons switch from single-spike activity to burst-firing mode. J Neurosci 19:599-609.

Beurrier C, Bioulac B, Hammond C (2000) Slowly inactivating sodium current (INaP) underlies single-spike activity in rat subthalamic neurons. J Neurophysiol 83:1951-1957.

Bevan MD, Wilson CJ (1999) Mechanisms underlying spontaneous oscillation and rhythmic firing in rat subthalamic neurons. J Neurosci 19:7617-7628.

Bevan MD, Wilson CJ, Bolam JP, Magill PJ (2000) Equilibrium potential of 
GABA(A) current and implications for rebound burst firing in rat subthalamic neurons in vitro. J Neurophysiol 83:3169-3172.

Bevan MD, Magill PJ, Hallworth NE, Bolam JP, Wilson CJ (2002) Regulation of the timing and pattern of action potential generation in rat subthalamic neurons in vitro by GABA-A IPSPs. J Neurophysiol 87:1348-1362.

Bevan MD, Atherton JF, Baufreton J (2006) Cellular principles underlying normal and pathological activity in the subthalamic nucleus. Curr Opin Neurobiol 16:621-628.

Biel M, Wahl-Schott C, Michalakis S, Zong X (2009) Hyperpolarizationactivated cation channels: from genes to function. Physiol Rev 89:847885.

Boyes J, Bolam JP, Shigemoto R, Stanford IM (2007) Functional presynaptic HCN channels in the rat globus pallidus. Eur J Neurosci 25:2081-2092.

Brown P (2003) Oscillatory nature of human basal ganglia activity: relationship to the pathophysiology of Parkinson's disease. Mov Disord 18:357363.

Bullis JB, Jones TD, Poolos NP (2007) Reversed somatodendritic I(h) gradient in a class of rat hippocampal neurons with pyramidal morphology. J Physiol 579:431-443.

Chan CS, Shigemoto R, Mercer JN, Surmeier DJ (2004) HCN2 and HCN1 channels govern the regularity of autonomous pacemaking and synaptic resetting in globus pallidus neurons. J Neurosci 24:9921-9932.

Chevaleyre V, Castillo PE (2002) Assessing the role of Ih channels in synaptic transmission and mossy fiber LTP. Proc Natl Acad Sci U S A 99:9538-9543.

Crossman AR (2000) Functional anatomy of movement disorders. J Anat 196:519-525

Crossman AR, Sambrook MA, Jackson A (1984) Experimental hemichorea/ hemiballismus in the monkey. Studies on the intracerebral site of action in a drug-induced dyskinesia. Brain 107:579-596.

DeLong MR (1990) Primate models of movement disorders of basal ganglia origin. Trends Neurosci 13:281-285.

Destexhe A, Mainen ZF, Sejnowski TJ (1998) Kinetic models of synaptic transmission. In: Methods in neural modeling (Koch C, Segev I, eds), pp 1-25. Cambridge, MA: MIT.

Do MT, Bean BP (2003) Subthreshold sodium currents and pacemaking of subthalamic neurons: modulation by slow inactivation. Neuron 39:109120.

Dreyfus FM, Tscherter A, Errington AC, Renger JJ, Shin HS, Uebele VN, Crunelli V, Lambert RC, Leresche N (2010) Selective T-type calcium channel block in thalamic neurons reveals channel redundancy and physiological impact of $I_{\text {Twindow. }}$ J Neurosci 30:99-109.

Fan Y, Fricker D, Brager DH, Chen X, Lu HC, Chitwood RA, Johnston D (2005) Activity-dependent decrease of excitability in rat hippocampal neurons through increases in I(h). Nat Neurosci 8:1542-1551.

Felix R, Sandoval A, Sánchez D, Gómora JC, De la Vega-Beltrán JL, Treviño CL, Darszon A (2003) ZD7288 inhibits low-threshold Ca ${ }^{2+}$ channel activity and regulates sperm function. Biochem Biophys Res Commun 311:187-192.

François C, Savy C, Jan C, Tande D, Hirsch EC, Yelnik J (2000) Dopaminergic innervation of the subthalamic nucleus in the normal state, in MPTPtreated monkeys, and in Parkinson's disease patients. J Comp Neurol 425:121-129.

Garden DL, Dodson PD, O’Donnell C, White MD, Nolan MF (2008) Tuning of synaptic integration in the medial entorhinal cortex to the organization of grid cell firing fields. Neuron 60:875-889.

Gillies A, Willshaw D (2006) Membrane channel interactions underlying rat subthalamic projection neuron rhythmic and bursting activity. J Neurophysiol 95:2352-2365.

Halliwell JV, Adams PR (1982) Voltage-clamp analysis of muscarinic excitation in hippocampal neurons. Brain Res 250:71-92.

Hallworth NE, Bevan MD (2005) Globus pallidus neurons dynamically regulate the activity pattern of subthalamic nucleus neurons through the frequency-dependent activation of postsynaptic $\mathrm{GABA}_{\mathrm{A}}$ and $\mathrm{GABA}_{\mathrm{B}}$ receptors. J Neurosci 25:6304-6315.

Hallworth NE, Wilson CJ, Bevan MD (2003) Apamin-sensitive small conductance calcium-activated potassium channels, through their selective coupling to voltage-gated calcium channels, are critical determinants of the precision, pace, and pattern of action potential generation in rat subthalamic nucleus neurons in vitro. J Neurosci 23:7525-7542.
Holderith NB, Shigemoto R, Nusser Z (2003) Cell type-dependent expression of HCN1 in the main olfactory bulb. Eur J Neurosci 18:344-354.

Karachi C, Grabli D, Baup N, Mounayar S, Tandé D, François C, Hirsch EC (2009) Dysfunction of the subthalamic nucleus induces behavioral and movement disorders in monkeys. Mov Disord 24:1183-1192.

Kass JI, Mintz IM (2006) Silent plateau potentials, rhythmic bursts, and pacemaker firing: three patterns of activity that coexist in quadristable subthalamic neurons. Proc Natl Acad Sci U S A 103:183-188.

Kita H, Chang HT, Kitai ST (1983) The morphology of intracellularly labeled rat subthalamic neurons: a light microscopic analysis. J Comp Neurol 215:245-257.

Kole MH, Bräuer AU, Stuart GJ (2007) Inherited cortical HCN1 channel loss amplifies dendritic calcium electrogenesis and burst firing in a rat absence epilepsy model. J Physiol 578:507-525.

Levy R, Hutchison WD, Lozano AM, Dostrovsky JO (2002) Synchronized neuronal discharge in the basal ganglia of parkinsonian patients is limited to oscillatory activity. J Neurosci 22:2855-2861.

London M, Häusser M (2005) Dendritic computation. Annu Rev Neurosci 28:503-532.

Lörincz A, Notomi T, Tamás G, Shigemoto R, Nusser Z (2002) Polarized and compartment-dependent distribution of $\mathrm{HCN} 1$ in pyramidal cell dendrites. Nat Neurosci 5:1185-1193.

Ludwig A, Budde T, Stieber J, Moosmang S, Wahl C, Holthoff K, Langebartels A, Wotjak C, Munsch T, Zong X, Feil S, Feil R, Lancel M, Chien KR, Konnerth A, Pape HC, Biel M, Hofmann F (2003) Absence epilepsy and sinus dysrhythmia in mice lacking the pacemaker channel HCN2. EMBO J 22:216-224.

Ludwin SK (1979) The perineuronal satellite oligodendrocyte. A role in remyelination. Acta Neuropathol 47:49-53.

Lüthi A, McCormick DA (1998) Periodicity of thalamic synchronized oscillations: the role of $\mathrm{Ca} 2+-$-mediated upregulation of Ih. Neuron 20:553563.

Magee JC (1998) Dendritic hyperpolarization-activated currents modify the integrative properties of hippocampal CAl pyramidal neurons. J Neurosci 18:7613-7624.

Magee JC (1999) Dendritic lh normalizes temporal summation in hippocampal CA1 neurons. Nat Neurosci 2:508-514.

Magill PJ, Bolam JP, Bevan MD (2001) Dopamine regulates the impact of the cerebral cortex on the subthalamic nucleus-globus pallidus network. Neuroscience 106:313-330.

Meurers BH, Dziewczapolski G, Bittner A, Shi T, Kamme F, Shults CW (2009) Dopamine depletion induced up-regulation of HCN3 enhances rebound excitability of basal ganglia output neurons. Neurobiol Dis 34:178-188.

Monteggia LM, Eisch AJ, Tang MD, Kaczmarek LK, Nestler EJ (2000) Cloning and localization of the hyperpolarization-activated cyclic nucleotidegated channel family in rat brain. Brain Res Mol Brain Res 81:129-139.

Notomi T, Shigemoto R (2004) Immunohistochemical localization of Ih channel subunits, HCN1-4, in the rat brain. J Comp Neurol 471:241-276.

Otsuka T, Murakami F, Song WJ (2001) Excitatory postsynaptic potentials trigger a plateau potential in rat subthalamic neurons at hyperpolarized states. J Neurophysiol 86:1816-1825.

Otsuka T, Abe T, Tsukagawa T, Song WJ (2004) Conductance-based model of the voltage-dependent generation of a plateau potential in subthalamic neurons. J Neurophysiol 92:255-264.

Pape HC, McCormick DA (1989) Noradrenaline and serotonin selectively modulate thalamic burst firing by enhancing a hyperpolarizationactivated cation current. Nature 340:715-718.

Ramanathan S, Tkatch T, Atherton JF, Wilson CJ, Bevan MD (2008) D2like dopamine receptors modulate $\mathrm{SK}_{\mathrm{Ca}}$ channel function in subthalamic nucleus neurons through inhibition of $\mathrm{Ca}_{\mathrm{v}} 2.2$ channels. J Neurophysiol 99:442-459.

Raz A, Vaadia E, Bergman H (2000) Firing patterns and correlations of spontaneous discharge of pallidal neurons in the normal and the tremulous 1-methyl-4-phenyl-1,2,3,6-tetrahydropyridine vervet model of parkinsonism. J Neurosci 20:8559-8571.

Robinson RB, Siegelbaum SA (2003) Hyperpolarization-activated cation currents: from molecules to physiological function. Annu Rev Physiol 65:453-480.

Santoro B, Chen S, Lüthi A, Pavlidis P, Shumyatsky GP, Tibbs GR, Siegelbaum SA (2000) Molecular and functional heterogeneity of hyper- 
polarization-activated pacemaker channels in the mouse CNS. J Neurosci 20:5264-5275.

Shah MM, Anderson AE, Leung V, Lin X, Johnston D (2004) Seizureinduced plasticity of $\mathrm{h}$ channels in entorhinal cortical layer III pyramidal neurons. Neuron 44:495-508.

Shen KZ, Johnson SW (2005) Dopamine depletion alters responses to glutamate and GABA in the rat subthalamic nucleus. Neuroreport $16: 171-174$

Shin M, Brager D, Jaramillo TC, Johnston D, Chetkovich DM (2008) Mislocalization of $\mathrm{h}$ channel subunits underlies $\mathrm{h}$ channelopathy in temporal lobe epilepsy. Neurobiol Dis 32:26-36.

Tachibana Y, Kita H, Chiken S, Takada M, Nambu A (2008) Motor cortical control of internal pallidal activity through glutamatergic and GABAergic inputs in awake monkeys. Eur J Neurosci 27:238-253.

Tkatch T, Baranauskas G, Surmeier DJ (2000) Kv4.2 mRNA abundance and A-type $\mathrm{K}^{+}$current amplitude are linearly related in basal ganglia and basal forebrain neurons. J Neurosci 20:579-588.

Tsay D, Dudman JT, Siegelbaum SA (2007) HCN1 channels constrain synaptically evoked $\mathrm{Ca} 2+$ spikes in distal dendrites of CA1 pyramidal neurons. Neuron 56:1076-1089.

Tsodyks MV, Markram H (1997) The neural code between neocortical pyramidal neurons depends on neurotransmitter release probability. Proc Natl Acad Sci U S A 94:719-723.
Urbain N, Gervasoni D, Soulière F, Lobo L, Rentéro N, Windels F, Astier B, Savasta M, Fort P, Renaud B, Luppi PH, Chouvet G (2000) Unrelated course of subthalamic nucleus and globus pallidus neuronal activities across vigilance states in the rat. Eur J Neurosci 12:3361-3374.

Wichmann T, DeLong MR (2003) Pathophysiology of Parkinson's disease: the MPTP primate model of the human disorder. Ann N Y Acad Sci 991:199-213.

Wichmann T, Bergman H, DeLong MR (1994) The primate subthalamic nucleus. III. Changes in motor behavior and neuronal activity in the internal pallidum induced by subthalamic inactivation in the MPTP model of parkinsonism. J Neurophysiol 72:521-530.

Williams SR, Mitchell SJ (2008) Direct measurement of somatic voltage clamp errors in central neurons. Nat Neurosci 11:790-798.

Williams SR, Stuart GJ (2000) Site independence of EPSP time course is mediated by dendritic $\mathrm{I}(\mathrm{h})$ in neocortical pyramidal neurons. J Neurophysiol 83:3177-3182.

Williams SR, Stuart GJ (2003) Voltage- and site-dependent control of the somatic impact of dendritic IPSPs. J Neurosci 23:7358-7367.

Williams SR, Christensen SR, Stuart GJ, Häusser M (2002) Membrane potential bistability is controlled by the hyperpolarization-activated current $\mathrm{I}(\mathrm{H})$ in rat cerebellar Purkinje neurons in vitro. J Physiol 539:469-483. 